\title{
How games induce cooperation? A study on the relationship between game features and we-intentions in an augmented reality game
}

\author{
Benedikt Morschheuser \\ Institute of Information Systems and Marketing, Karlsruhe Institute of Technology, Germany \\ Corporate Research, Robert Bosch GmbH, Germany \\ benedikt.morschheuser@kit.edu
}

\section{Marc Riar}

Chair of Information Systems IV, University of Mannheim, Germany mriar@mail.uni-mannheim.de

\section{Juho Hamari}

Gamification Group, Tampere University of Technology, Finland

Gamification Group, University of Turku, Finland

juho.hamari@tut.fi

\author{
Alexander Maedche \\ Institute of Information Systems and Marketing, Karlsruhe Institute of Technology, Germany \\ alexander.maedche@kit.edu
}

DOI: Reference: https://doi.org/10.1016/j.chb.2017.08.026

To appear in: Computers in Human Behavior

Please cite this article as:

Benedikt Morschheuser, Marc Riar, Juho Hamari, Alexander Maedche, How games induce cooperation? A study on the relationship between game features and we- intentions in an augmented reality game, Computers in Human Behavior (2017), doi: 10.1016/j.chb. 2017.08.026 


\title{
How games induce cooperation? A study on the relationship between game features and we-intentions in an augmented reality game
}

\begin{abstract}
Seamless cooperation between individuals is essentially a crucial aspect of any successful endeavor. A host of literature has been published in the academic realm about how cooperation could be cultivated. However, true cooperation often forms organically without external enforcement. Recently, there has been one special example of a context where cooperation seemed to have effortlessly sprung up between people who might not even have had previous connections. The context is video/online games; games such as Ingress, Pokémon Go, and World of Warcraft bind people together to work against insurmountable odds and to overcome jointly held challenges. Organizations of many types have recently begun to gamify their structures and services in order to cultivate such seamless cooperation. However, before this potential of games can be successfully wielded outside video games, we need to understand better how games are able to cultivate such cooperation. Therefore, in this study we investigate how games can induce and cultivate we-intention of working as a group. Specifically, we investigate how cooperative game features affect different forms of group dynamics and how they further translate into we-intentions. We employ data from users of the augmented reality game Ingress $(\mathrm{N}=206)$. The results show that cooperative game features induce we-intentions via positively increasing group norms, social identity, joint commitment, attitudes toward cooperation, and anticipated positive emotions. The findings imply that practitioners who are looking to increase cooperation should find that gamification inspired by cooperative game design is beneficial and preferable over individual-based gamification efforts.
\end{abstract}

Keywords: Gamification, cooperation, online games, location-based games, augmented reality, weintention 


\section{Introduction}

Cooperation is an anchor of our society and a key ability of people, who are working, studying, and carrying out most leisure activities together to achieve shared goals. During the past decade, modern information \& communication technologies (ICT) that digitally connect people around the globe have birthed completely new forms of cooperation in organizations and beyond. A large variety of collaborative technologies, such as online communities (Hutter, Hautz, Füller, Mueller, \& Matzler 2011), crowdsourcing platforms (Geiger \& Schader 2014), or instant messaging services (Shen, Cheung, \& Lee 2013) have emerged that facilitate working together anytime and across geographical borders. However, many studies report that it is challenging to motivate people to adopt and use such collaborative technologies (Arazy, Gellatly, Brainin, \& Nov 2016; Hutter et al. 2011; C.-P. Lin \& Bhattacherjee 2008; K.-Y. Lin \& Lu 2011; Wasko \& Faraj 2005; Zhao \& Zhu 2014). Thus, much work has sought to understand which factors drive people to cooperate (Bagozzi \& Dholakia 2002, 2006; Tsai \& Bagozzi 2014) and how design features in information systems and services can support and cultivate cooperative behaviors (Jung, Schneider, \& Valacich 2010; Straub, Gimpel, Teschner, \& Weinhardt 2015; Valacich, Dennis, \& Connolly 1994; Zhang, Venkatesh, \& Brown 2011).

Concerning video games, it can be observed that, in many games, cooperation emerges effortlessly; people start to pool individual efforts, cooperate seamlessly even against the most unimaginable odds, and express strong enthusiasm while acting together (C.-H. Chen, Sun, \& Hsieh 2008; Cole \& Griffiths 2007; Ducheneaut, Yee, Nickell, \& Moore 2006; Scharkow, Festl, Vogelgesang, \& Quandt 2015; Teng \& Chen 2014; Yee 2006). Thus, today, practitioners turn to games for inspiration on how to design information systems, services, and organizational structures more cooperatively (Bui, Veit, \& Webster 2015; Morschheuser, 
Maedche, \& Walter 2017b; Ribeiro, Farinha, Pereira, \& Mira da Silva 2014; Schacht, \& Maedche 2015; Thom, Millen, Dimicco, \& Street 2012). This trend can be understood as part of the gamification movement, which represents the use of game elements and mechanics outside traditional video game environments (Hamari, Koivisto, \& Sarsa 2014; Huotari \& Hamari 2017). Initial empirical studies indicate that applying game mechanics and features of cooperative games, such as point systems that reward cooperation (Blohm, Bretschneider, Leimeister, \& Krcmar 2011; Y. Chen \& Pu 2014; Siu, Zook, \& Riedl 2014; Thom et al. 2012), team competitions (Peng \& Hsieh 2012; Chen \& Pu 2014), or virtual worlds with avatars (Rico, Martínez-Muñoz, Alaman, Camacho, \& Pulido 2011) can positively influence cooperation in various contexts. However, we still lack a comprehensive understanding of how games cultivate cooperation (Liu, Li, \& Santhanam 2013; Hamari \& Keronen 2017b; Morschheuser et al. 2017b), which keeps us from successful wielding the potential of cooperative games in gamification (Bui et al. 2015; Liu, Santhanam, \& Webster 2017; Morschheuser, Hamari, \& Koivisto 2017a).

Recently, the concept of we-intentions has gained attention in information system (IS) research concerning understanding cooperation with collaborative technologies. Compared to typically studied individual intentions, the concept of we-intention relies on the idea that true cooperation requires collective intentions and therefore cannot be analyzed only as the sum of individual intentions (Searle 1990; Tuomela 2000). The concept is increasingly gaining attention in IS research, in order to study cooperation and cooperative behaviors in online communities (Bagozzi \& Dholakia 2002; Cheung \& Lee 2010; Dholakia, Bagozzi, \& Pearo 2004; Shen et al. 2013; Shen, Cheung, Lee, \& Chen 2011; Tsai \& Bagozzi 2014) and crowdsourcing systems (Bagozzi \& Dholakia 2006; Shen, Lee, \& Cheung 2014; Shen, Lee, Cheung, \& Chen 2009). Owing to the strong similarities between such virtual communities 
and online games, this theoretical framework provides excellent support for investigating cooperation in games.

Therefore, in this paper, we empirically investigate how games cultivate we-intentions of working as a group by drawing on cooperation theory (Tuomela 2000) and particularly the concept of we-intentions (Bagozzi \& Dholakia 2002; Tsai \& Bagozzi 2014; Tuomela 2000). On the basis of survey data, gathered in the context of the augmented reality game Ingress that engages people in generating an interactive map with cultural points of interest, we seek to enhance current understandings of how engagement with cooperative game features induce we-intentions via group dynamics, such as group norms, positive and negative anticipated emotions, social identity, joint commitment, and attitudes toward cooperation. Further, we investigate whether engagement with individualistic game features - such as private badges, points or levels - that are currently often used in the context of collaborative technologies (Hamari et al. 2014; Morschheuser, Hamari, \& Koivisto 2016) influence these effects. This paper summarizes this study's findings and discusses theoretical and practical implications.

\section{Theoretical Background and Research Model}

\subsection{We-intentions and their antecedents}

Researchers have put much effort into theoretically conceptualizing and studying the phenomenon of cooperation from different perspectives, including philosophy (Gilbert 1989; Tuomela 2000), game theory (Nash 1953), and social psychology (Johnson 2003). Commonly, pure or full-blown cooperation is typically considered to consist of collective social actions, in which more than one person act jointly toward a common goal (e.g. carrying a table jointly) (Gilbert 1989; Tuomela 2000). 
According to Tuomela (2000, 2011), such cooperation is characterized and determined by a collective we-intention of group members towards a shared goal. Thus, recently, studies have commonly drawn on the concept of we-intention (Searle 1990; Tuomela 2000, 2011) to operationalize cooperation in groups. In contrast to typically investigated personal intentions, which capture individual commitment to an action, we-intentions involve a 'we-perspective', expressing a collective commitment to participate in a cooperative action (Bratman 1997; Searle 1990; Tuomela 2000, 2011). Therefore, we-intentions are explicitly formulated with reference to a collective entity of we or $u s$, which expresses the intention to jointly perform an activity together with others: "We intend to do X jointly" (Bratman 1997; Searle 1990; Tuomela 2000, 2011).

Since the inception of these conceptualizations, the we-intentions-operationalization has been applied in the study of cooperation in several technology-mediated contexts, such as wikis, crowdsourcing platforms, instant messaging services, and other social communities (Bagozzi \& Dholakia 2002, 2006; Shen et al. 2014; Tsai \& Bagozzi 2014). These studies have shown that we-intention is a strong proximal determinant of cooperation and provides a more comprehensive explanation of user participation in group efforts than traditionally investigated personal intentions.

Although the adoption and use of collaborative technologies have been frequently investigated in IS research (C.-P. Lin \& Bhattacherjee 2008; K.-Y. Lin \& Lu 2011; Majchrzak, Rice, Malhotra, King, \& Ba 2000), studies have mostly investigated individual intentions (i-intentions). The we-intention concept has been largely overlooked by the repetitive application of theories such as the technology acceptance model (Davis 1989), the theory of reasoned action (Fishbein \& Ajzen 1975), and the theory of planned behavior (Ajzen 1991), all of which solely investigate intentions from an individual perspective. 
However, it is obvious that participation and cooperation in online communities and other collaborative technologies are commonly a group activity. Typically, users adopt and use such technologies for a common reason or to achieve a shared goal. Thus, cooperation in such collaborative technologies is increasingly investigated through the concept of we-intention in recent IS research (De Oliveira \& Huertas 2015; Shen et al. 2013; Tsai \& Bagozzi 2014). Guided by Bagozzi and Dholakia (Bagozzi \& Dholakia 2002, 2006; Dholakia et al. 2004; Tsai \& Bagozzi 2014), a variety of efforts have been made to empirically investigate the cooperation of users in social communities, crowdsourcing approaches, or instant messaging services (Table 1). A synthesis of extant research indicates that individual factors, such as attitudes (Tsai \& Bagozzi 2014) and anticipated emotions (Bagozzi \& Dholakia 2002; Tsai \& Bagozzi 2014) as well as social antecedents, such as joint commitment (Shen et al. 2014 2009; Tuomela 2000), social identity (Bagozzi \& Dholakia 2002; Tsai \& Bagozzi 2014), and group norms (Bagozzi \& Dholakia 2002; Oliveira \& Huertas 2015; Tsai \& Bagozzi 2014) influence we-intentions to work together with collaborative technologies.

More importantly, it has remained unclear which features in these technologies are responsible for invoking we-intentions and how specific features can, in the end, engage more cooperation. Moreover, the particular context of cooperation in games and gamified approaches has been largely ignored in prior we-intention research. 
Table 1: We-intention and its antecedents in collaborative technologies

\begin{tabular}{|c|c|c|}
\hline Work & Context & Significant antecedents of we-intention \\
\hline $\begin{array}{l}\text { De Oliveira \& } \\
\text { Huertas } 2015\end{array}$ & $\begin{array}{l}\text { Participation in the social } \\
\text { network Facebook }\end{array}$ & $\begin{array}{l}\text { Group norms, social identity, subjective } \\
\text { norms, social enhancement, maintaining } \\
\text { interpersonal interconnectivity }\end{array}$ \\
\hline Tsai \& Bagozzi 2014 & $\begin{array}{l}\text { Participation in a Chinese } \\
\text { social network }\end{array}$ & $\begin{array}{l}\text { Group norms, subjective norms, social } \\
\text { identity, anticipated emotions, attitudes } \\
\text { toward contributing, desire }\end{array}$ \\
\hline $\begin{array}{l}\text { Shen, Lee, \& } \\
\text { Cheung } 2014\end{array}$ & $\begin{array}{l}\text { Crowdsourcing participation } \\
\text { in wikis }\end{array}$ & Commitment to the community, team trust \\
\hline $\begin{array}{l}\text { Shen, Cheung, \& } \\
\text { Lee } 2013\end{array}$ & $\begin{array}{l}\text { Collaboration via instant } \\
\text { messaging }\end{array}$ & $\begin{array}{l}\text { Group norms, social identity, perceived } \\
\text { critical mass }\end{array}$ \\
\hline $\begin{array}{l}\text { Cheung, Chiu, \& Lee } \\
2011\end{array}$ & $\begin{array}{l}\text { Participation in the social } \\
\text { network Facebook }\end{array}$ & $\begin{array}{l}\text { Group norms, social enhancement, } \\
\text { entertainment value, maintaining } \\
\text { interpersonal interconnectivity, social } \\
\text { presence }\end{array}$ \\
\hline $\begin{array}{l}\text { Shen, Cheung, Lee, } \\
\& \text { Chen } 2011\end{array}$ & $\begin{array}{l}\text { Collaboration via instant } \\
\text { messaging }\end{array}$ & Group norms, social identity, desire \\
\hline Cheung \& Lee 2010 & $\begin{array}{l}\text { Participation in the social } \\
\text { network Facebook }\end{array}$ & Social identity, subjective norms \\
\hline $\begin{array}{l}\text { Shen, Lee, Cheung, } \\
\& \text { Chen } 2009\end{array}$ & $\begin{array}{l}\text { Crowdsourcing participation } \\
\text { in wikis }\end{array}$ & $\begin{array}{l}\text { Joint commitment, mutual agreement, } \\
\text { personal outcome expectations, community- } \\
\text { related outcome expectations }\end{array}$ \\
\hline $\begin{array}{l}\text { Bagozzi \& Dholakia } \\
2006\end{array}$ & $\begin{array}{l}\text { Participation in Linux user } \\
\text { groups }\end{array}$ & $\begin{array}{l}\text { Social identity, attitudes toward contributing, } \\
\text { negative anticipated emotions, perceived } \\
\text { behavioral control }\end{array}$ \\
\hline $\begin{array}{l}\text { Dholakia, Bagozzi, \& } \\
\text { Pearo } 2004\end{array}$ & $\begin{array}{l}\text { Participation in virtual } \\
\text { communities }\end{array}$ & $\begin{array}{l}\text { Group norms, social identity, mutual } \\
\text { agreement, desire }\end{array}$ \\
\hline $\begin{array}{l}\text { Bagozzi \& Dholakia } \\
2002\end{array}$ & $\begin{array}{l}\text { Participation (chatting) in } \\
\text { different virtual } \\
\text { communities }\end{array}$ & $\begin{array}{l}\text { Social identity, positive anticipated emotions, } \\
\text { desire }\end{array}$ \\
\hline
\end{tabular}

\subsection{Cooperation and games}

Games are a pinnacle form of hedonic systems that invoke rich motivational experiences and excite masses of people (Hamari 2015a; Ryan, Rigby, \& Przybylski 2006; Vesa, Hamari, Harviainen, \& Warmelink 2017; Yee 2006). Since the first video games, researchers were fascinated by the psychological and behavioral outcomes of games and made efforts to understand the design characteristics, which are responsible for the rich motivational 
experiences and the different behavioral effects of games (Choi \& Kim 2004; Hamari \& Keronen 2017b; Hamari \& Tuunanen 2014; Malone 1981; Ryan et al. 2006; Yee 2006). One particular behavior that can be observed in many games is cooperation. Especially in the context of online games that utilize the internet to bring people together, cooperation seems to effortlessly spring up between people who might not even have had previous connections (Cole \& Griffiths 2007; Velez \& Ewoldsen 2013; Yee 2006).

Several studies have revealed that popular online games, such as World of Warcraft, Star Wars Galaxies, or Ultima Online attract masses of people by providing them with rich social experiences while playing together (Przybylski, Rigby, \& Ryan 2010; Rigby \& Ryan 2011; Yee 2006; Zhong 2011). Research has showed that players greatly enjoy the social interaction and cooperation in such games (Przybylski et al. 2010; Velez \& Ewoldsen 2013; Yee 2006). In all these games, people help each other voluntarily to accomplish common missions and goals, strongly interact with one another to discuss in-game strategies and opportunities, share comprehensive knowledge about game contents in forums and wikis, and form groups (known as guilds, clans or factions) that persist over time. Further, several empirical studies in the context of video games and gamified systems highlight the positive effects of cooperation in games compared to competition. For instance, Y. Chen and $\mathrm{Pu}$ (2014), Marker and Staiano (2015), Peng and Hsieh (2012), and Plass et al. (2013) found that cooperative approaches can lead to higher engagement with games or gamified systems compared to competitive approaches. Positive effects on goal commitment (Peng \& Hsieh 2012), motivation (Marker \& Staiano 2015), and intentions to recommend a game (Plass et al. 2013) have also been found to be effects of games that are designed to support cooperation. However, little research has analyzed the design features and dynamics in games and gamified systems that enable and promote cooperation (Bui et al. 2015; Liu et al. 2013; Morschheuser et al. 2017b). 
Drawing on social interdependence theory (Johnson 2003), games (Liu et al. 2013) and their game features (Morschheuser et al. 2017b) have been classified as cooperative, competitive, or individualistic based on the applied goal structures. Individualistic game features refer thereby to game features such as private badges or levels that provide gameful experiences based on individual goals, without invoking interdependencies to goals of other players. In contrast, cooperative game features provide gameful experiences by using cooperative goal structures such as shared goals for a group of players (Morschheuser et al. 2017b). Similar to this deductive approach, several empirical studies have highlighted the roles of shared goals and have provided further details on key characteristics of cooperative games. By investigating popular online and video games, Rocha, Mascarenhas, and Prada (2008) observed that shared goals and specific game mechanics can be found in games in which players cooperate. They report that games invoke shared goals for a group of players or positive correlations between individual goals, in order to provide clear reasons for playing together (El-Nasr et al. 2010; Rocha et al. 2008). Examples include the implementation of a team challenge or a shared puzzle (El-Nasr et al. 2010; Liu et al. 2013; Morschheuser et al. 2017b; Plass et al. 2013). Furthermore, the application of game mechanics that equip players with different abilities and action possibilities have been found to be typical design patterns of cooperative games. Examples include the implementation of complementary abilities (e.g. characters with different skills), abilities that can only be used on other players, limited resources, or special rules that support all players of a team (El-Nasr et al. 2010; Rocha et al. 2008). Finally, communication features that can be used to discuss common goals and strategies have been highlighted as important aspects of cooperative games (Beznosyk et al. 2012; Ducheneaut et al. 2006; Velez \& Ewoldsen 2013). Similar patterns were identified by Zagal, Rick, and Hsi (2006), who have explored cooperative design patterns in board games. 
Based to the synthesis of this research, and inspired by Choi and Kim (2004), who have investigated design features of online games, three key design features of cooperative games can be summarized: 1) cooperative games apply goal structures that give one reasons to cooperate, 2) cooperative games provide special rules and mechanics that enable and support cooperative behavior, and 3) cooperative games provide communication features to allow social interaction (Beznosyk, Quax, Coninx, \& Lamotte 2012; Choi \& Kim 2004; Ducheneaut et al. 2006; Velez \& Ewoldsen 2013). In the following, we build on these categories to specify what we consider as cooperative game features (Figure 1).

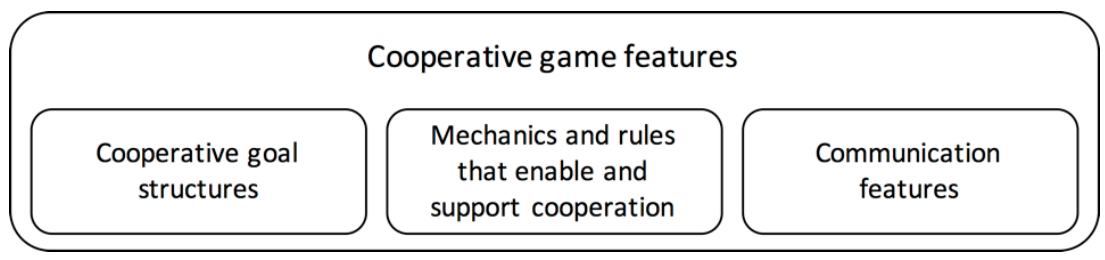

Figure 1: Key design features of cooperative games

Several studies on cooperative video games and gamified systems support the assumption that there is a correlation between the engagement with such cooperative game features and cooperation in games. Based on observations of player behaviors, El-Nasr et al. (2010) identified that shared goals and several game mechanics that enable and support cooperation, especially complementary abilities, influence enjoyment, excitement, and cooperative behaviors in popular cooperative video games. Further, research that investigated cooperative games and their game features' effects, indicates that applying design features of cooperative games (e.g. shared goals) can induce cooperative behaviors (Y. Chen \& Pu 2014; Goh \& Lee 2011; Morschheuser et al. 2017b; Peng \& Hsieh 2012; Plass et al. 2013) and can positively influence social interaction (Hamari \& Koivisto 2015; Scheiner 2015). Inspired by these findings, we seek to better understand this possible correlation between cooperative game features and cooperation by investigating how engagement (cf. use and interest) with cooperative game features induce we-intentions. 
Since cooperative games address similar social needs as other online communities (Rigby 2014; Scharkow et al. 2015; Tsai \& Pai 2014; Yee 2006), we expect that the dynamics invoked by cooperative game features are comparable to the socio-psychological processes identified in previous research on we-intention in virtual communities. Therefore, we focus our research on typical antecedents of we-intentions in virtual communities (Table 1) and empirically investigate whether and how game design features induce we-intentions to play with others in a group. Figure 2 summarizes our proposed model. The underlying hypotheses are explained in the following.

\subsection{The roles of shared goals}

Since the beginning of video game research, challenging goals have been highlighted as a core feature of games (Malone 1981). By setting challenging goals and providing instant positive feedback concerning goal achievement (Deterding 2015; Malone 1981, 1982), games provide motivational affordances for the experience of competence satisfaction, mastery, or achievement (Huotari \& Hamari 2017). According to the goal-setting theory (Locke \& Latham 1990), the setting of challenging goals such as those applied in games and gamification approaches (Bui et al. 2015; Deterding 2015; Hamari 2013, 2017; Huotari \& Hamari 2017; Jung et al. 2010; Rigby 2014) can influence motivation and behavior. Several studies that have investigated the influences of particular game features in the context of gamification research underpin this theoretical assumption. For instance, Jung et al. (2010) have shown that the integration of goal-setting and performance feedback in the form of a leaderboard in an innovation community can increase the performance of participants, while Hamari (2017) has indicated that goal-setting with badges can positively influence social interaction in communities. 
Cooperative games typically provide challenges based on goals that are shared with other players (El-Nasr et al. 2010; Rocha et al. 2008). Empirical studies indicate that such shared goals can have strong effects on enjoyment, excitement, and cooperative behaviors in popular cooperative video games (El-Nasr et al. 2010). This outcome is in line with Tuomela's (2000, p. 26) cooperation theory, which claims that "cooperation in the fullest sense involves acting towards a collective goal".

Previous research that has drawn on we-intention has operationalized the influence of shared goals by investigating a group member's perceived group norms (e.g. Dholakia et al. 2004; Oliveira \& Huertas 2015; Tsai \& Bagozzi 2014). Group norms capture the perceived overlap between individual goals and the goals of other members in a group (Tsai \& Bagozzi 2014), and has been found to be a good indicator of internalization processes that occur when people act together (Bagozzi \& Dholakia 2002; Dholakia et al. 2004; Tsai \& Bagozzi 2014). From a theoretical perspective, strong group norms that reflect the values and goals a user shares with a group implicitly generate consensus among members of a group. Thus, strong group norms promise to positively impact participation of group members in a joint group activity (Dholakia et al. 2004). Several studies have shown that strong group norms lead to mutual agreement among group members (Dholakia et al. 2004) and a higher level of we-intention (Cheung et al. 2011; Dholakia et al. 2004; Shen et al. 2013). In this respect, we expect that cooperative game features that explicitly specify shared goals or intertwine individual goals will create correlation between players' goals and will invoke group norms. Grounded in previous research about we-intentions in virtual communities, we further expect that strong group norms directly influence the we-intentions of players in a group to act together (cf. Cheung et al. 2011; Dholakia et al. 2004; Oliveira \& Huertas 2015; Shen et al. 2013). Therefore, we posit: 
H1a: Engagement with cooperative game features positively relates to group norms.

H1b: Stronger group norms lead to higher levels of we-intention.

Players of cooperative games that engage individuals to cooperate towards a shared goal might evaluate the motivational consequences of contributing or not contributing toward a collective goal. A player might imagine the pleasant aspects of cooperating with other players and possible negative emotional consequences of not playing together to achieve a shared goal. The positive and negative emotional reactions that arise from evaluating the consequences of achieving or not achieving a shared goal (Perugini \& Bagozzi 2001) has been identified as a predictor of cooperative behavior in similar scenarios (Bagozzi \& Dholakia 2002, 2006; Tsai \& Bagozzi 2014). The theoretical underpinning of these anticipated emotions can be found in the model of goal-directed behavior (MGB) (Perugini \& Bagozzi 2001). Perugini and Bagozzi (2001) suggest that the prospects of (not) achieving a goal-directed action influence desires and the intentions to act, and thereby the de facto behaviors. Based on studies that have shown positive relationships between personal anticipated emotions and we-intentions in several virtual communities (Table 1), we assume that cooperative game features that engage players to cooperate in order to achieve shared goals will induce anticipated emotions, which mediate the influence of game features on weintentions. Accordingly, we hypothesize:

H2a: Engagement with cooperative game features positively relates to positive anticipated emotions.

H2b: Greater levels of positive anticipated emotions are associated with higher levels of weintention.

H2c: Engagement with cooperative game features positively relates to negative anticipated emotions. 
H2d: Greater levels of negative anticipated emotions are associated with higher levels of weintention.

\subsection{The roles of social identification processes}

People that are part of a social group, such as players in a team of cooperative games, reflect their personal positions in the group. This socio-psychological process that is characterized by the personal self-awareness of his or her membership in a group is defined as a user's social identity (Bagozzi \& Lee 2002; Ellemers, Kortekaas, \& Ouwerkerk 1999; Tajfel 1982). Social identity has cognitive, affective, and evaluative components: the cognitive awareness of one's membership in a group (cognitive), a sense of emotional involvement in the group (affective), and the group-based self-esteem (evaluative) (Ellemers et al. 1999). From social identity theory, we learn that identities can be activated in situations (salience) in which the situational conditions allow access to achieving group goals (Stets \& Burke 2000). Cooperative game features can be viewed as such situational conditions that provide access to achieving group goals and may therefore activate individuals' social identities. Further, cooperative game features that allow one to interact with other group members may increase one's emotional tie to the group and may influence one's affective commitment. Previous literature implies that expressing mutual welfare and by believing in the virtue of a relationship forms a foundation for trust (McAllister 1995; Rempel, Holmes, \& Zanna 1985). Ultimately, it can be assumed that a trust relationship can be established by reciprocatively displaying cooperative behavior, since such behavior demonstrates aspirations for mutual welfare and a belief in the virtue of a relationship. This may intensify the emotional tie to membership of a group. Cooperative games typically provide direct feedback to individual behavior and allow one to reflect on the own performance in relation to others (Morschheuser et al. 2017b; Zagal et al. 2006). Such performance feedback may influence individuals to act as others in the group want them to act, which can increase an individual's self-esteem in the group (Bagozzi \& Dholakia 2002; 
Zagal et al. 2006). Consequently, the use of cooperative game features and the personal success that may be attached to using such features may lead to a positive evaluation of an individual's own value in the group and thus may affect his or her group-based self-esteem. Previous research on we-intention showed that a social identity positively influences weintentions (Table 1). Therefore, we hypothesize:

H3a: Engagement with cooperative game features positively relates to social identity.

H3b: Greater levels of social identity are associated with higher levels of we-intention.

\subsection{The roles of joint commitment}

Cooperative games typically apply features that allow players to communicate and interact with other players (Choi \& Kim 2004; Ducheneaut et al. 2006; El-Nasr et al. 2010; Yee 2006). This involves features for verbal and written communication, such as virtual chat (Ducheneaut et al. 2006), but also functions that can be used for non-verbal interactions. Examples of the latter are in-game abilities that can be used to interact with other players in a virtual world (e.g. virtual objects and virtual gifts) or abilities that can be used to positively influence other players (e.g. healing abilities) (El-Nasr et al. 2010; Rocha et al. 2008). Some cooperative games, such as Portal2 or LittleBigPlanet, also give players opportunities to use the body of an avatar in order to express feelings and communicate with other players via virtual body language (cf. C.-Y. Hsu, Tung, Wang \& Wang 2014). A key aspect of these features is that players can use them as a medium to express willingness and commitment to participate in a joint action. For instance, a player who buys a virtual item that increases the attack value of all the players in his area shows his willingness to go into battle together with others. Also, avatar-based body language, which encourages other players to stick together, can serve as an instrument to express commitment to a joint action (C.-Y. Hsu et al. 2014). 
Theory on cooperation (Gilbert 1989; Tuomela 1995, 2000) emphasizes that participants' joint commitment to a collective action is crucial to the cultivation of cooperation. Thus, joint commitment has been identified as an antecedent of we-intentions (Shen et al. 2014): "Weintention involves a joint commitment to contribute to the realization of the content of the weintention" (Tuomela 2000, p. 63). Compared to personal commitments, joint commitment involves a mutual agreement by every member to participate in a joint activity ("we do $\mathrm{X}$ jointly"). In other words, joint commitment can be defined as the common knowledge that all participants jointly express their readiness to be under the obligation to participate in a joint action and are jointly committed to do their part of "X" (Gilbert 1999; Shen et al. 2009; Tuomela 1995, 2000). We assume that communication features in cooperative games may support the joint commitments, similar to other virtual communities (Bagozzi \& Dholakia 2002; Shen et al. 2014, 2009), since they enable players to communicate and express personal beliefs and obligations. Further, we expect that cooperative game features that enable and support cooperative interaction as described above, can be an important instrument to express joint commitment. Based on this discussion, we assume that:

H4a: Engagement with cooperative game features positively relates to joint commitment.

H4b: Joint commitment positively relates to we-intention.

\subsection{The roles of attitudes}

In the context of games and gamification approaches, many studies have investigated the relationships between individual attitudes and the behavioral intention to use a game or a gamified system (Hamari \& Koivisto 2015a, 2015b; C.-L. Hsu \& Lu 2004; for a review, see Hamari \& Keronen 2017b). An individual's attitude toward a behavior represents the psychological evaluation of a planned behavior along a positive-to-negative dimension (Ajzen 1991). Attitudes are cognitive variables that influence decision-making and lead to behavioral 
intentions (Armitage \& Conner 2001). Research has revealed that hedonic aspects of games (Hamari \& Keronen 2017b; Wu \& Liu 2007) and social features that increase social recognition (Hamari \& Koivisto 2015a, 2015b) influence attitudes to use gamified systems and games. However, very few studies have investigated attitudes and intentions to play together with others.

According to research on we-intentions, attitudes toward a cooperative act has been identified as a key psychological predictor of we-intention (Bagozzi \& Dholakia 2006; Tsai \& Bagozzi 2014). In the context of games, this relationship between attitude and we-intention is expected to be similar. Thus, we posit:

H5a: Engagement with cooperative game features positively relates to attitudes toward playing together with others.

H5b: Greater levels of attitudes toward playing together with others are associated with higher levels of we-intention.

\subsection{The mediating roles of group dynamics}

Extensive research that has been conducted in order to investigate the antecedents of weintention (Table 1) revealed that group norms, positive and negative anticipated emotions, social identity, joint commitment, and attitudes toward cooperating together with a group explain we-intentions very well (Bagozzi \& Dholakia 2002, 2006; Dholakia et al. 2004; Shen et al. 2009; Tsai \& Bagozzi 2014). Especially concerning collaborative technologies - such as online communities, crowdsourcing platforms and messaging services - these group dynamics seem to predict we-intention and cooperation (Table 1). We extend this research by investigating whether and how cooperative game features induce we-intentions. As hypothesized, we suspect that cooperative features in games influence all these group 
dynamics in order to invoke and cultivate we-intentions. Consequently, there is no obvious reason to suspect that these variables do not fully mediate the relationships between cooperative game features and we-intentions. Accordingly, we posit:

H6: The effect between engagement with cooperative game features and we-intention is fully mediated by group norms, positive and negative anticipated emotions, social identity, joint commitment, and attitudes toward cooperating with others.

\subsection{The roles of other, non-cooperative game features}

Popular discussion pertaining to online games such as World of Warcraft or Pokémon Go highlight that people easily and organically form highly cohesive teams in games (Brown \& Thomas 2006; Ducheneaut, Yee, Nickell, \& Moore 2007), indicating that games seem to uniquely cater for the development of we-intentions between individuals. However, games are often complex and characterized by the uses of various game features (Björk \& Holopainen 2005; Vesa et al. 2017) that allow a user to play them alone or together with others (Marker \& Staiano 2015; Peng \& Hsieh 2012). Currently, most game companies develop games in a way that allows the player to play both in single-player and/or cooperative multiplayer modes by integrating various game features. While we mainly hypothesize that games' positive effects on group dynamics and we-intention stem from a game's cooperative features, it is possible that the single-player features also have a role in the formation of cooperation in games. According to Morschheuser et al. (2017b) and Liu et al. (2013), only cooperative game features are designed to invoke cooperative goal structures that have been defined as a key antecedent of 'full-blown' cooperation (Tuomela 2000). In contrast, non-cooperative (cf. single-player/individualistic) game features are detached from cooperative goals and characterize individual goal structures, invoking personal intentions that lead to individual play rather than we-intentions and cooperation. Several studies have indicated clear 
differences in behavioral outcomes between cooperative, individualistic, and competitive designs in games and gamified systems (Y. Chen \& Pu 2014; Goh \& Lee 2011; Marker \& Staiano 2015; Peng \& Hsieh 2012; Plass et al. 2013; Siu et al. 2014). Based on these considerations and empirical results, we hypothesize that cooperative game features induce we-intentions and positively affect group dynamics, hypothesizing that individualistic game features have no effects on group dynamics that invoke we-intentions. Accordingly:

H7a: Engagement with individualistic game features is not associated with we-intentions.

H7b: Engagement with individualistic game features is not associated with group dynamics.

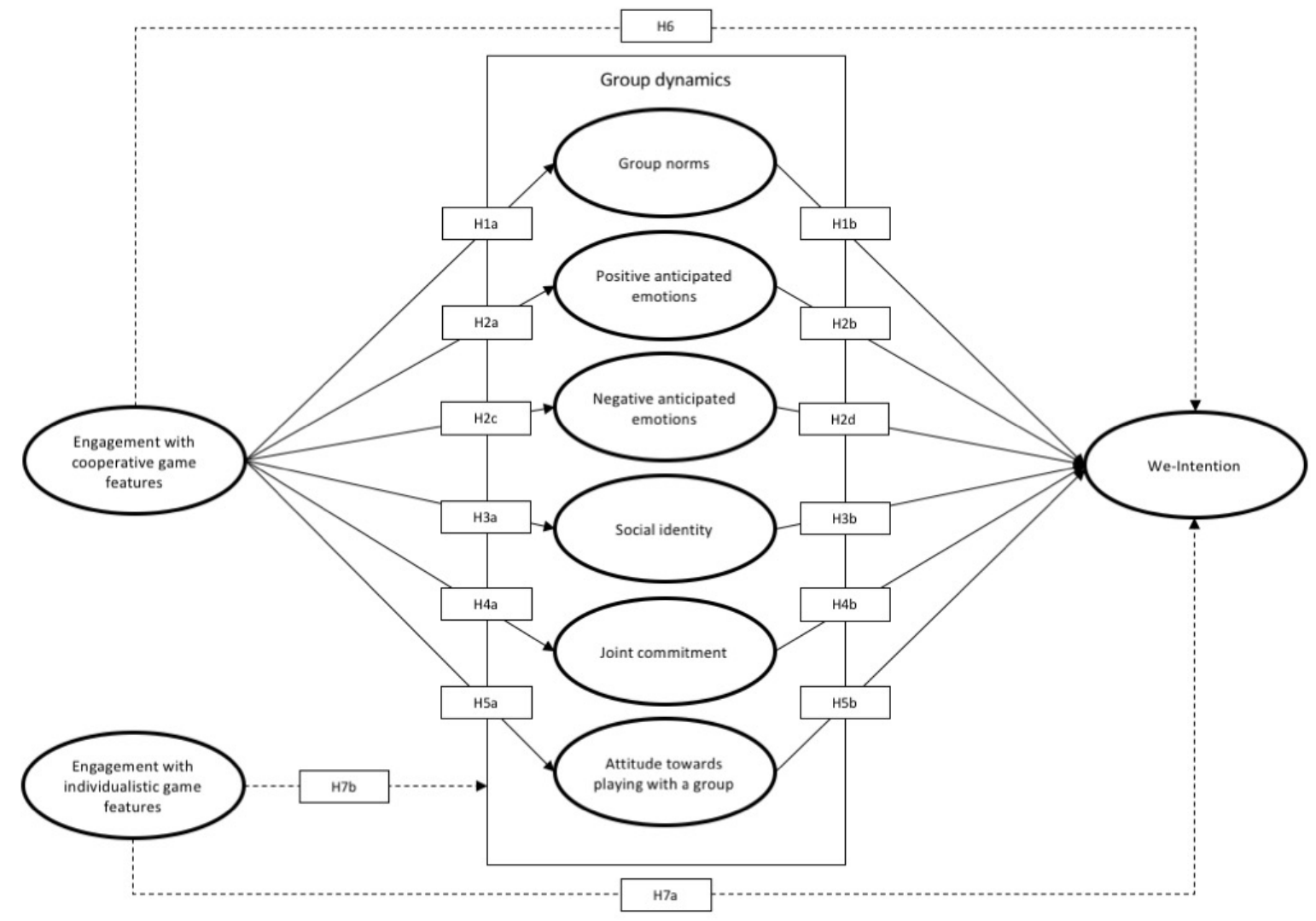

Figure 2: The research model 


\section{The Empirical Study}

\subsection{Data}

We gathered the data from players of Ingress, a popular game with over 11 million downloads in more than 200 countries (Smith 2015; Takahashi 2014). Ingress is an augmented reality game that relies on a map of the real world and extends reality with location-based virtual objects, the so-called portals, at places of public art (Hulsey \& Reeves 2014). Ingress players can use an app on their mobile phones, the so-called scanner, to find the location of such portals and create new virtual portals, which are connected by their location to landmarks in the real world. The game rules define that these portals should be created at places of public art, for instance, at statues, graffiti, or buildings with outstanding architecture. Main goal in the game is to collect points by creating and conquering these virtual portals and linking them together in order to create triangular fields in virtual space. The scoring system is based on these fields (the more space is covered by a field, the more points one can get). Two factions (Enlightened vs. Resistance) compete against each other for the portals and fields. The winning team with the most points (Mind Units) in a predefined period is determined at regular intervals. Since the portals and other game content are created by the community of players, Ingress can be also specified as a gamified crowdsourcing approach (Morschheuser et al. 2016; 2017a) that creates an interactive map with cultural points of interest (Hulsey \& Reeves 2014). The user-generated database has been used as source for other services, such as the Pokémon Go app.

Ingress seems apt for this study, because participants display strong cooperative behavior in their faction. Research has identified that, besides factors such as fun and exploration, the community in a faction and their shared progress is of great importance to Ingress players (Sheng 2013). Further, there are many regional associations of Ingress players on the internet 
that organize regional meetups, teach one another, and discuss strategies to achieve regional supremacy ${ }^{1}$.

All of the above mentioned cooperative design features are implemented in Ingress. First, the game defines clear goals for all members of a faction. The common goal is to obtain more Mind Units (MU) than the other team in predefined time intervals (Checkpoints and cycles). Second, different mechanics and rules are implemented that allow players to cooperatively support each other, such as applying Mods, upgrading portals, and recharging Resonators of other players or the possibility to share items among faction members with Capsules. Third, players can interact with each other in Ingress using an integrated chat feature (COMM). In addition to these technical features, the Ingress community regularly hosts events where people can meet to socialize, exchange strategies, and play Ingress together (e.g. Mission Days, XM Anomalies and First Saturday events). Ingress also uses several more individualistic features, such as a level system, badges, and personal (agent) statistics, which are designed to invoke individualistic goal structures and allow to play the game as a single player.

We tested our proposed model with data from Ingress players gathered via an online questionnaire. We invited the participants in different open Ingress communities on Google+ by posting a short description of the survey and a link to it. In addition, we asked the moderators and owners of several communities to re-post the link in their private groups so as to extend the range. The survey was active from May 4, 2016 to October 30, 2016. In that time, about 800 Ingress players responded to our call, and 233 players participated in the questionnaire. Similar to previous we-intention research, we asked the participants to identify a group of Ingress players they regularly play with (Bagozzi \& Dholakia 2006; Tsai \&

\footnotetext{
${ }^{1}$ https://www.ingress.com/community/directory.
} 
Bagozzi 2014) so as to induce respondents to think about a real group of people and to better prepare them for the questions to follow. Since our study focuses on cooperative play, we excluded players who reported that they don't regularly play in a group from the analysis, resulting in 206 valid responses. Table 2 outlines the sample characteristics. Respondents were entered into a prize draw for one of three $€ 15$ Amazon gift coupons.

Table 2: Demographic information about respondents, including gender, age, days since last playing Ingress, and time playing Ingress

\begin{tabular}{|r|r|r|r|r|r|r|}
\hline Gender & $\#$ & $\%$ & \multicolumn{2}{|c|}{ When did you last play Ingress? } & $\#$ & $\%$ \\
\hline Female & 62 & 30.1 & & today & 134 & 65.0 \\
\hline Male & 144 & 69.9 & & yesterday & 59 & 28.6 \\
\hline & & & & Time playing Ingress & $\#$ & $\%$ \\
\hline Age & $\#$ & $\%$ & & $<1$ years & 54 & 26.2 \\
\hline$<20$ & 19 & 9.2 & & 1 to 2 years & 60 & 29.1 \\
\hline 20 to 29 & 49 & 23.8 & & 2 to 3 years & 54 & 26.2 \\
\hline 30 to 39 & 70 & 34.0 & & $>3$ years & 38 & 18.4 \\
\hline 40 to 49 & 50 & 24.3 & & & & \\
\hline 50 and over & 18 & 8.7 & & & & \\
\hline
\end{tabular}

The questionnaire was answered by people from 15 countries. The average respondent age was 34.6. The sample consisted of $30.1 \%$ female and $69.9 \%$ male participants; $26.2 \%$ have been playing Ingress for less than a year, 29.1\% between 1 and 2 years, 26.2\% between 2 and 3 years, and $18.4 \%$ for more than three years. Respondents typically reported playing Ingress multiple times a day $(68.4 \%$, on a 6 -item scale anchored between rarely and multiple times a day), play for 48 hours (median) per month, and have at least completed high school (89.4\%) or a Bachelor's degree (43.8\%).

\subsection{Measurement}

We adopted the operationalization of we-intention and its antecedents from previous sources (see Table 1; Table 3). The items to measure the engagement with cooperative game features in Ingress were developed in two stages: 
First, we played Ingress ourselves and conducted semi-structured interviews with eight experienced players to identify cooperative game features in Ingress. The interviews were conducted via telephone and lasted approximately 40 minutes. The participants ( 5 male, 3 female, average age 28, all had been playing Ingress regularly for at least six months) were recruited in Ingress user groups on Google+. We guided the interviews along a questionnaire that contained a large set of Ingress game design features, which we derived from the official Ingress user guide ${ }^{2}$. Following Morschheuser et al.'s (2017b) classification framework, we asked the experts to separate the Ingress game features into individualistic, competitive, and cooperative game features. First, we comprehensively introduced these different feature categories. Next, we asked the participants to specify the nature (individualistic, cooperative, competitive) of the identified Ingress game design features on a 5-point Likert scale (strongly disagree - strongly agree) (see Appendix 1). We asked them to think aloud so we could take notes on their reasoning for placing the game features in the various categories. Several game features were perceived by the participants as having both competitive traits (at an intergrouplevel) as well as cooperative traits (at an intragroup level). For such cooperative-competitive features (e.g. factions), we carefully identified the cooperative aspects. Based on the interviews, we noted that 12 features were mainly perceived as cooperative features and eight features were classified primarily as individualistic (Appendix 2). Based on these identified cooperative and individualistic game features, we developed items that measured a user's engagement with these features. Together, we used these items to operationalize the engagement with cooperative / individualistic game features in Ingress. We treated the constructs as formative, as its exposure happens through using those features or by perceiving them as important. Further, the identified features were not explicitly interchangeable, which contradicts reflective use (Diamantopoulos \& Siguaw 2006).

\footnotetext{
${ }^{2}$ https://support.ingress.com/hc/en-us.
} 
Second, we conducted a pre-study to evaluate the developed measurements and the constructs we adopted from the existing we-intention literature. We conducted the survey on two days in October 2015. In sum, 110 participants took part in the pre-study, which were recruited on Ingress user groups different to the groups of the main study. Since the pre-study revealed largely a high validity level of the used items, we made only small adjustments. We improved some of the items that had been developed to measure engagement with cooperative game features and added a third we-intention item based on Shen et al.'s work (2009).

Table 3: The measurement items

We-intention (WE-I) Tsai and Bagozzi (2014); Bagozzi and Lee (2002); Shen et al. (2009)

(1) I intend that our group (i.e. myself and the group that I identified before) play Ingress together sometime during the next 4 weeks. (7-point "disagree" - "agree" scale)

(2) We (i.e., I and the group that I identified before) intend to play Ingress together sometime during the next 4 weeks. (7-point "disagree" - "agree" scale)

(3) We (i.e., I and the group that I identified before) plan to play Ingress together sometime during the next 4 weeks. (7-point "disagree" - "agree" scale)

Group norms (GN)

Tsai and Bagozzi (2014); Bagozzi and Dholakia (2002)

Playing Ingress together sometime within the next 4 weeks with the group you identified before can be considered a goal. For each of the people listed below and for yourself, please estimate the strength to which each holds the goal. (7-point "very weak" - "very strong" scales)

(1) Average of the strength of group members' goal

(2) Strength of own goal

Positive anticipated emotions (PAE)

Tsai and Bagozzi (2014); Perugini and Bagozzi (2001)

If I am able to play Ingress with the group I identified before during the next 4 weeks, I will feel: (1) excited, (2) delighted, (3) happy, (4) satisfied, (5) proud, (6) self-assured, (7) relief, (8) glad (7-point "not at all" - "moderately" - "very much" scales)

Negative anticipated emotions (NAE)

Tsai and Bagozzi (2014); Perugini and Bagozzi (2001)

If I am unable to play Ingress with the group I identified before during the next 4 weeks, I will feel: (1) angry, (2) frustrated, (3) guilty, (4) ashamed, (5) disappointed, (6) depressed, (7) worried, (8) uncomfortable, (9) anxious

(7-point "not at all" - "moderately" - "very much" scales)

Joint commitment (JC)

Shen et al. (2009)

(1) We (i.e., I and the group that I identified before) all know that all members are jointly committed to performing their parts of the common tasks. (7-point "disagree" - "agree" scale) 
(2) We (i.e., I and the group that I identified before) all know that all members are jointly committed to contributing to the common success. (7-point "disagree" - "agree" scale)

(3) We (i.e., I and the group that I identified before) all know that all members are jointly committed to helping each other. (7-point "disagree" - "agree" scale)

(4) We (i.e., I and the group that I identified before) all know that all members are jointly committed to achieving the common goals. (7-point "disagree" - "agree" scale)

Social identity (SI)

Bagozzi and Lee (2002); Tsai and Bagozzi (2014)

Cognitive social identity

(1) How would you express the degree of overlap between your personal identity and the identity of the group you identified before, when you are actually playing with members of the group?

(8-point graphical "Far apart" - "Complete overlap" scale)

(2)Please indicate to what degree your self-image overlaps with the identity of the group you identified before, as you perceive it. (7-point "not at all" - "moderately" - "very much" scale)

Affective social identity

(1) How attached are you to the group you identified before?

(7-point "not at all" - "moderately" - "very much" scale)

(2) How strong would you say your feelings of belongingness are toward the group you identified before?

(7-point "not at all" - "moderately" - "very much" scale)

Evaluative social identity

(1) I am a valuable member of the group I identified before.

(7-point "does not describe me at all" - "describe me moderately well" - "describe me very well" scale)

(2) I am an important member of the group I identified before.

(7-point "does not describe me at all" - "describe me moderately well" - "describe me very well" scale)

Attitudes toward cooperation (ATT)

Tsai and Bagozzi (2014); Ajzen (1991)

Playing Ingress together with the group I identified before sometime during the next 4 weeks is:

(1) "Foolish" - "Wise", (2) "Bad" - "Good", (3) "Harmful" - "Beneficial" and (4) "Punishing" -

"Rewarding" (7-point semantic differential)

Engagement with cooperative game features (CG)

Constructed formative measure

(1) How important is it to you to create control fields in order to obtain Mind Units (MU)?

(2) How often do you create control fields in order to obtain Mind Units (MU)?

(3) How important is to you to see the faction's progress during a cycle?

(4) How often do you look at the faction's progress during a cycle?

(5) How important is it to you to upgrade portals of other players? (upgrade = deploy Mods, deploy additional Resonators, upgrade Resonators to higher level)

(6) How often do you upgrade portals of other players? (upgrade = deploy Mods, deploy additional Resonators, upgrade Resonators to a higher level)

(7) How important is it to you to recharge Resonators of other players?

(8) How often do you recharge Resonators of other players?

(9) How important is it to you to communicate with other players via chat?

(10) How often do you communicate with other players via chat?

(11) How important are First Saturday (FS) events to you?

(12) How often do you participate in First Saturday (FS) events?

(13) How important are XM Anomalies to you?

(14) How often do you participate in XM Anomalies?

(15) How important are Mission Days to you?

(16) How often do you participate in Mission Days?

(7-point "not at all important" - "very important" / "never" - "every time" scales) 
(1) How often do you look at your personal achievements? (e.g. Mission Badges, Medals, Action Points)

(2) How important are your personal achievements to you? (e.g. Mission Badges, Medals, Action Points)

(3) How often do you look at your personal level?

(4) How important is your personal level to you?

(5) How often do you look at the visualization of your avatar?

(6) How important is the visualization of your avatar to you?

(7) How often do you look at your personal stats? (statistics about number of portals, MUs, links, control fields, etc., under your control)

(8) How important are your personal stats to you? (statistics about number of portals, MUs, links, control fields, etc., under your control)

(9) How often do you play missions?

(10) How important is being able to play missions to you?

(11) How often do you use Power Cubes?

(12) How important are Power Cubes to you?

(7-point "not at all important" - "very important" / "never" - "every time" scales)

\subsection{Validity and reliability}

We tested the model via the component-based PLS-SEM in SmartPLS 3 (Ringle, Wende, \& Becker 2015), which is considered a suitable structural equation modeling (SEM) method for prediction-oriented studies such as this, while covariance-based SEM is better suited for testing which models best fit the data (Anderson \& Gerbing 1988; Chin, Marcolin, \& Newsted 2003). We also used component-based SEM, since the model includes both formative and reflective constructs (e.g. see Lowry \& Gaskin 2014).

We assessed convergent validity (see Table 4) with two metrics: average variance extracted (AVE) and composite reliability (CR). Convergent validity was met (each construct's AVE should be $>0.5$, each construct's CR should be $>0.7$ ) (Fornell \& Larcker 1981). We examined the discriminant validity first through the comparison of the square root of the AVE of each construct to all of the correlations between it and other constructs (see Fornell \& Larcker 1981) (Table 4), where all of the square roots of the AVEs should be greater than the correlations between the corresponding construct and any other construct (Chin 1998; Jöreskog \& Sörbom 1996). Second, we checked discriminant validity through the HTMT criterion. In our data, no value between two constructs exceeded 0.85 , which is the threshold 
for discriminant validity (Henseler, Ringle, \& Sarstedt 2015). Third, we assessed discriminant validity by confirming that each item had the highest loading with its corresponding construct. We can conclude that the discriminant validity and the reliability were acceptable. The sample size $(\mathrm{N}=206)$ satisfies several different criteria for the lower bounds of sample size for PLSSEM (Anderson \& Gerbing 1988; Chin 1998).

Table 4: Validity and reliability

\begin{tabular}{|l|l|l|l|l|l|l|l|l|l|l|l|}
\hline & AVE & CR & CG & IG & ATT & GN & JC & NAE & PAE & SI & WE-I \\
\hline CG & n/a & $\mathrm{n} / \mathrm{a}$ & $\mathrm{n} / \mathrm{a}$ & & & & & & & & \\
\hline IG & $\mathrm{n} / \mathrm{a}$ & $\mathrm{n} / \mathrm{a}$ & $\mathrm{n} / \mathrm{a}$ & $\mathrm{n} / \mathrm{a}$ & & & & & & & \\
\hline ATT & 0.631 & 0.872 & 0.451 & 0.269 & $\mathbf{0 . 7 9 4}$ & & & & & & \\
\hline GN & 0.734 & 0.847 & 0.415 & 0.219 & 0.423 & $\mathbf{0 . 8 5 7}$ & & & & & \\
\hline JC & 0.693 & 0.900 & 0.439 & 0.364 & 0.450 & 0.366 & $\mathbf{0 . 8 3 3}$ & & & & \\
\hline NAE & 0.680 & 0.950 & 0.232 & 0.115 & 0.223 & 0.195 & 0.237 & $\mathbf{0 . 8 2 4}$ & & & \\
\hline PAE & 0.623 & 0.929 & 0.535 & 0.392 & 0.566 & 0.390 & 0.552 & 0.457 & $\mathbf{0 . 7 8 9}$ & & \\
\hline SI & 0.637 & 0.897 & 0.575 & 0.317 & 0.397 & 0.416 & 0.520 & 0.402 & 0.619 & $\mathbf{0 . 7 9 8}$ & \\
\hline WE-I & 0.760 & 0.950 & 0.503 & 0.226 & 0.591 & 0.566 & 0.551 & 0.370 & 0.657 & 0.594 & $\mathbf{0 . 8 7 2}$ \\
\hline
\end{tabular}

\subsection{Results}

First, investigating the direct relationships between the different game features and weintentions (without including the group dynamics mediators), we found a statistically significant association between engagement with cooperative game features and we-intention $(\beta=.476, \mathrm{p}<.001)$, but no significant effect between engagement with individualistic gamification features and we-intention $(\beta=.087, \mathrm{p}>.1)$. In total, the engagement with these game features account for $25.7 \%$ of the variance of we-intention, out of which cooperative game features explain all most all the variance. 
Second, when adding the hypothesized mediators pertaining to group dynamics into the model, we found that, together, engagement with the game features and group dynamics account for $62.8 \%$ of the variance of we-intention (Figure 3). Further, we found that these group dynamics together fully mediate the effect between engagement with cooperative game features and we-intention. Therefore, hypothesis 6 is supported.

Engagement with cooperative game features accounts mainly for the variance of group dynamics to the following magnitudes: $17.5 \%$ of group norms, $32.0 \%$ of positive anticipated emotions from playing together, 5.4\% of negative anticipated emotions from missing out, $33.7 \%$ of social identity, $23.2 \%$ of joint commitment, and $21.1 \%$ of attitudes toward playing with the group. Based on how much variance is accounted for in the model, we can concluded that a) engagement with cooperative game features accounts for about one-quarter of users we-intentions directly, however, b) the effect of engagement with cooperative game features also significantly increases all facets of group dynamics, which c) further increases the model's explanatory power towards we-intentions up to $62.8 \%$. Therefore, we can further conclude that cooperative game features and the mediating group dynamics are a powerful set of predictors for people willing to work together.

The results pertaining to the hypotheses about the relationships between engagement with cooperative game features and singular facets of group dynamics indicate that engagement with cooperative game features is positively associated with all the constructs of group dynamics: Hla group norms $(\beta=.393, \mathrm{p}<.01)$, H2a positive anticipated emotions $(\beta=.449$, $\mathrm{p}<.01) H 2 c$ negative anticipated emotions $(\beta=.233, \mathrm{p}<.05) H 3$ a social identity $(\beta=.536, \mathrm{p}$ $<.01)$, H4a joint commitment $(\beta=.348, \mathrm{p}<.01)$, and H5a attitude $(\beta=.410, \mathrm{p}<.01)$ (see Figure 3 and Table 5). 
Concerning the relationships between group dynamics and we-intentions, the results indicate that group dynamics are associated with we-intentions in the following manner: H1b group norms $(\beta=.253, \mathrm{p}<.01)$, H2b positive anticipated emotions $(\beta=.254, \mathrm{p}<.01)$, H3b social identity $(\beta=.155, \mathrm{p}<.1)$, H4b joint commitment $(\beta=.151, \mathrm{p}<.05)$, and H5b attitude $(\beta=$ $.205, \mathrm{p}<.01)$ are positively associated with we-intentions. However, there is no evidence for a significant relationship between $H 2 d$ negative anticipated emotions and we-intentions $(\beta=$ $.063, \mathrm{p}>.1)($ see Figure 3 and Table 5).

In the complete model with group dynamics, we found that engagement with individualistic game features also have no significant effect on we-intention in total $(\beta=.019, \mathrm{p}>.1)$. In absolute terms, our results thus indicate that $\mathrm{H} 7 \mathrm{a}$ is supported. However, if we investigate the relationship between individualistic game features and group dynamics, we find that this relationship is more complex. Our findings show that engagement with individualistic game features can negatively affect we-intention $(\beta=-.115, \mathrm{p}<.05)$, compensated by invoking of positive anticipated emotions $(\beta=.204, \mathrm{p}<.01)$ and joint commitment $(\beta=.218, \mathrm{p}<.05)$. Consequently, $\mathrm{H} 7 \mathrm{a}$ and $\mathrm{H} 7 \mathrm{~b}$ were not fully supported. Combining cooperative game features with other, more individualistic features seems to be able to influence the emergence of weintentions in positive but also in negative ways. Overall, however, the influence of individualistic game features on group dynamics and we-intentions is very low, and can almost be neglected compared to the strong relationships between cooperative game features, group dynamics, and we-intentions. 


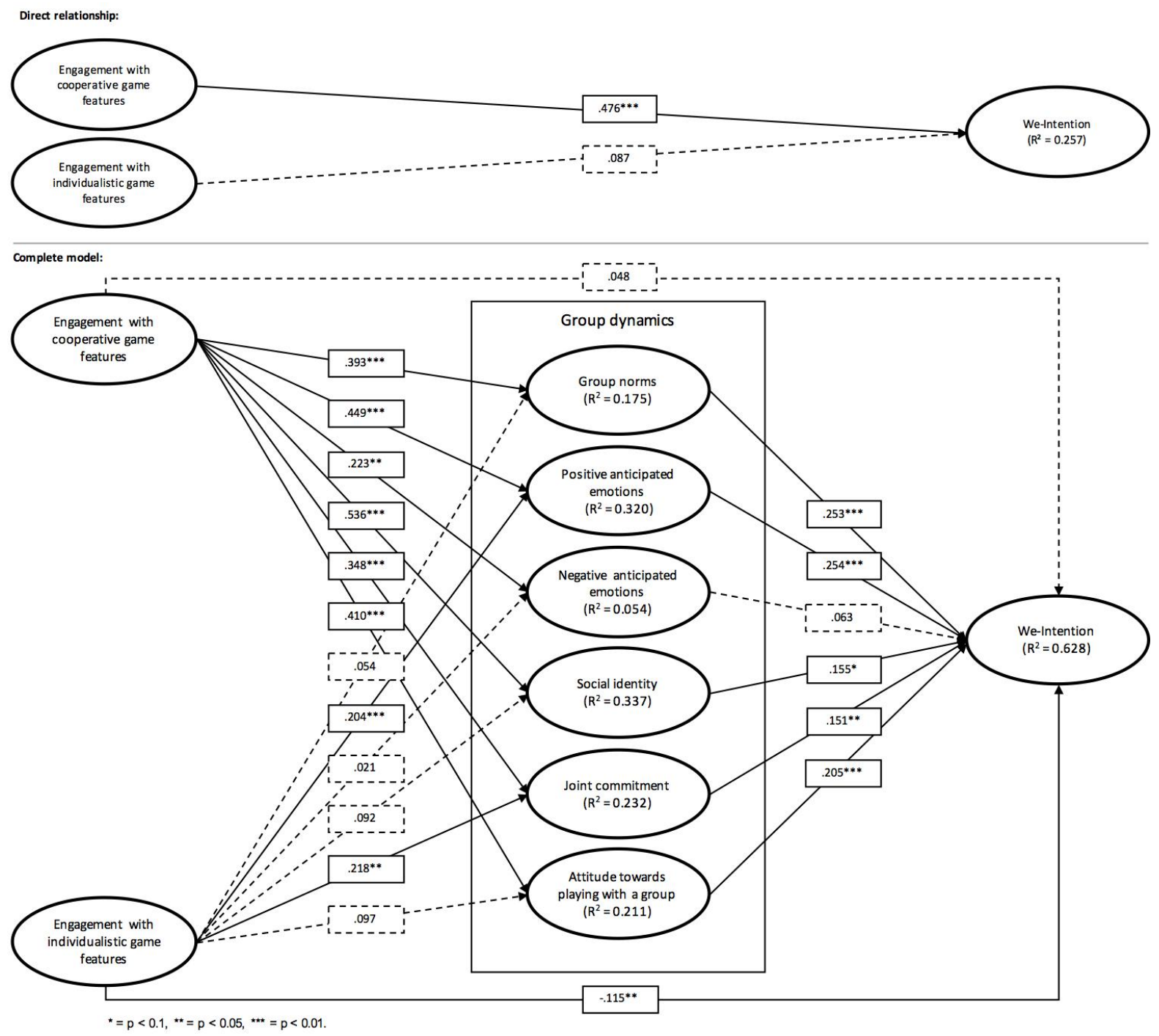

Figure 3: Results

Table 5: Results

\begin{tabular}{|l|l|l|l|l|l|l|}
\hline Independent variable & Dependent variable & Beta & Cl95 LO & Cl95 HI & $\mathbf{p}$ \\
\hline \multirow{5}{*}{ The relationships between engagement with cooperative game features and group dynamics } \\
\hline \multirow{4}{*}{$\begin{array}{l}\text { Cooperative game } \\
\text { features }\end{array}$} & Group norms & 0.393 & 0.258 & 0.541 & 0.000 \\
\cline { 2 - 6 } & Positive emotions & 0.449 & 0.349 & 0.599 & 0.000 \\
\cline { 2 - 6 } & Negative emotions & 0.223 & 0.060 & 0.408 & 0.012 \\
\cline { 2 - 6 } & Social identity & 0.536 & 0.413 & 0.642 & 0.000 \\
\cline { 2 - 6 } & Joint commitment & 0.348 & 0.210 & 0.527 & 0.000 \\
\cline { 2 - 6 } & Attitude & 0.410 & 0.250 & 0.582 & 0.000 \\
\hline \multirow{5}{*}{ The relationships between engagement with individualistic game features and group dynamics } \\
\hline \multirow{2}{*}{$\begin{array}{l}\text { Individualistic game } \\
\text { features }\end{array}$} & Group norms & 0.054 & -0.103 & 0.261 & 0.559 \\
\cline { 2 - 6 } & Positive emotions & 0.204 & 0.077 & 0.374 & 0.008 \\
\hline
\end{tabular}




\begin{tabular}{|c|c|c|c|c|c|}
\hline & Negative emotions & 0.021 & -0.145 & 0.252 & 0.830 \\
\hline & Social identity & 0.092 & -0.029 & 0.261 & 0.212 \\
\hline & Joint commitment & 0.218 & 0.047 & 0.395 & 0.014 \\
\hline & Attitude & 0.097 & -0.076 & 0.328 & 0.338 \\
\hline \multicolumn{6}{|c|}{ The relationship between group dynamics and we-intention } \\
\hline Group norms & \multirow[t]{6}{*}{ We-intention } & 0.253 & 0.145 & 0.356 & 0.000 \\
\hline Positive emotions & & 0.254 & 0.078 & 0.392 & 0.002 \\
\hline Negative emotions & & 0.063 & -0.026 & 0.169 & 0.207 \\
\hline Social identity & & 0.155 & 0.003 & 0.320 & 0.055 \\
\hline Joint commitment & & 0.151 & 0.024 & 0.263 & 0.011 \\
\hline Attitude & & 0.205 & 0.078 & 0.347 & 0.003 \\
\hline \multicolumn{6}{|c|}{ The total effect between engagement with game features and we-intention } \\
\hline $\begin{array}{l}\text { Cooperative game } \\
\text { features }\end{array}$ & We-intention & 0.495 & 0.352 & 0.647 & 0.000 \\
\hline $\begin{array}{l}\text { Individualistic game } \\
\text { features }\end{array}$ & We-intention & 0.019 & -0.075 & 0.243 & 0.814 \\
\hline
\end{tabular}

\section{Discussion}

In this study, we have investigated how games can induce and cultivate we-intention of working as a group. Specifically, we investigated how engagement with cooperative game features affect different forms of group dynamics and how they further translate into weintentions. We employed data from Ingress users $(\mathrm{N}=206)$, a popular location-based augmented reality game. The results show that cooperative game features can induce weintentions (directly explains one-quarter of the variance), whereas individualistic game features seem to have no direct effect on we-intentions. Further, this study revealed that the relationship between cooperative game features and we-intention is fully mediated by group norms, social identity, joint commitment, attitudes toward cooperation, and anticipated positive emotions. 
The study findings extend previous research in several ways. First, by empirically investigating how game design features can invoke we-intentions in games, this study closes a gap in current game (Goh \& Lee 2011; Liu et al. 2013) and gamification research (Bui et al. 2015; Y. Chen \& Pu 2014; Morschheuser et al. 2016). In addition to previous research that has focused on the behavioral outcomes (Goh \& Lee 2011; Marker \& Staiano 2015; Peng \& Hsieh 2012; Plass et al. 2013; Siu et al. 2014) and the design features of cooperative games (El-Nasr et al. 2010; Rocha et al. 2008; Zagal et al. 2006), this study connected both research streams and provided a comprehensive understanding of how engaging with such features can invoke collective intentions towards cooperative behavior. Further, this study has contributed to better understanding the effects of different game features in the sense that the results show that cooperative game features are positively related to we-intentions, while individualistic features are not. Therefore, these findings provide not only a novel contribution for understanding cooperation and participation in multiplayer games, such as Ingress, Pokémon Go, and World of Warcraft. Moreover, the knowledge we gathered can easily be transferred to current gamification research that investigates the differences between various game features in order to derive more precise design principles for designing successful gamification approaches (cf. Morschheuser et al. 2016; 2017a; 2017b; Hamari et al. 2014).

Second, our results provided support for the postulations that enriching ICT with gamification that promote shared goals instead of competition or individualistic goals may support digital cooperation (Morschheuser et al. 2017b; Peng \& Hsieh 2012). The present results support this notion by demonstrating that engagement with cooperative game features significantly relates to group dynamics, which operationalize the presence of shared goals. Especially, the strong relationship between group norm and cooperative game features are an indication for the presence of a shared goal between users in a group, since group norms represent the "attempt of individuals to meet idealized values or goals, shared with others" (Tsai \& Bagozzi 2014, p. 
147). Further, the identified influences of cooperative game features on anticipated emotions regarding achieving a shared goal and joint commitment to contribute to the realization of a shared goal, support this theory. Thus, our study can act as an anchoring point for future research into the effects of singular cooperative game features such as shared goals on psychological and behavioral outcomes of individuals in groups.

Third, our findings extend previous we-intention research (Dholakia et al. 2004; Oliveira \& Huertas 2015; Tsai \& Bagozzi 2014) that have neglected we-intention formation in games. Although the influence of design features on individual intentions in games and gameinspired approaches (i.e. gamification) have often been investigated (Hamari \& Keronen 2017b; Hamari \& Koivisto 2015a; Hsiao \& Chiou 2012; Wu \& Liu 2007), to our best knowledge, no other study has investigated we-intentions in this context. More importantly, little knowledge exists about how design features of information systems can influence weintentions. Our study results suggest that cooperative games are particularly efficient at invoking we-intentions. This finding not only contributes to the general understanding of weintentions, but also extends previous research in the sense that the results highlight the use of cooperative game features as a promising approach to invoke we-intentions.

Considering our results in the context of recent we-intention research (Table 1), we confirmed that group norms, social identity, joint commitment, attitudes toward cooperation, and anticipated positive emotions explain changes in we-intention reasonably well, also in the context of games. This significant overlap between our study and previous we-intention research contributes to the generalizability of the presented results and provides a foundation for bringing community research and game research closer together. This implies that game and gamification researchers should also turn to existing community research, and vice versa, in order to extend understandings of digital cooperation. 


\subsection{Practical implications}

Clearly, cooperation is of great importance in society today; we work, study, and carry out most leisure activities together. However, true cooperation often forms organically without external enforcement and is hard to cultivate. Many practitioners face the challenge of designing organizational structures and digital communities that promote cooperation, without knowing how design features can promote cooperation. When looking at video/online games, one can observe that cooperation effortlessly arises between people who might not even have had previous connections, and not just between individuals, but across a wide spectrum of people. To better understand how the potential of games can be successfully wielded in nongame organizations and information systems, this study has investigated how games are able to cultivate cooperation. The study results support the hypothesis that engagement with cooperative game features can influence collective intentions (we-intentions) of working in a group. This can provide practical insights for those seeking to cultivate cooperation in digital communities and organizations.

Our results suggest that cooperative design features in games - such as shared goals, cooperation enabling game mechanics and rules, and communication possibilities - offer great and as yet untapped potential for cultivating cooperation outside games. Designers of information systems and collaborative technology who seek to cultivate cooperation should consider the implementation of such design features known from cooperative games when gamifying their systems (Huotari \& Hamari 2017; Morschheuser et al. 2017a; 2017b).

In particular, our findings recommend the implementation of gamification features that influence group norms, invoke positive emotions when cooperating, and increase a member's identification with a group, in order to induce we-intentions and cultivate cooperation. First, designers and managers of communities should consider increasing the overlap of individual 
goals by carefully intertwining goals (El-Nasr et al. 2010; Rocha et al. 2008) or defining shared goals, such as team challenges or missions that can be completed by a group of users (Morschheuser et al. 2017b), to strengthen group norms. Second, the implementation of features that provide motivational rewards, such as the experience of mastery, competence, and social relatedness (Ryan et al. 2006), for achieving shared goals should be considered so as to increase the anticipated emotions of joint actions. Third, those seeking to cultivate cooperation should work on the representation and attractiveness of groups (cf. Tsai \& Bagozzi. 2014), and should implement features that can trigger self-reflection processes (Bagozzi \& Lee 2002; Ellemers et al. 1999) in order to support the shaping of members' identification with a group. Cooperative games such as Ingress, Pokémon Go, or World of Warcraft provide a treasure of examples of concrete design features that can easily be transferred to other environments. For instance, Ingress uses competing factions and defines the victory of the own team as a clear shared goal for all players in a faction. Several game features, such as leaderboards that visualize the regional supremacy of a faction and its members, as well as story and media items that explain and motivate the shared goals, are implemented to support the cooperative goal structures and may influence group norms in factions, as well as in their locally organized subgroups. To support members' identification with a group, we recommend the use of uniform colors and logos that can convey a clear group affiliation, statistics for direct comparison between players that enable social categorization (Turner 1975), and visual representations of users by avatars that can initiate self-reflection processes (Bessière, Seay, \& Kiesler 2007; Christoph, Dorothée, \& Peter 2009), similar to Ingress. Examples such as virtual goods that have been found to influence a user's social identity (Huang 2012) and could be used in some games as gifts to express commitment to other players, have already found their way from games (Hamari 2015b; Hamari \& Keronen 2017a) into online communities, such as Facebook (Huang 2012). 
Further, our findings imply that practitioners who seek to increase cooperation should find that gamification inspired by cooperative games is more beneficial and preferable to individual-based gamification. We found that individualistic game features can have negative effects on we-intention, which in our study have been compensated through small positive effects on group dynamics. Individualistic game features are designed to motivate personal goals and try to promote egotistical behavior (Morschheuser et al. 2017b). Previous research in the context of sports and education (for a review, see Johnson \& Johnson 1989, p. 173) indicate that mixing cooperative goal structures with individualistic goal structures can negatively affect the relationships between a group's members, since egotistical motives and behaviors may harm cooperative efforts and trust among group members. Such aspects could explain the negative relationships between individualistic game features and we-intention. On the other hand, our findings revealed that individualistic game features are positively related with positive anticipated emotions to play with others and joint commitment. We suspect that intertwining personal goals with the goals of others (El-Nasr et al. 2010; Rocha et al. 2008)such as in Ingress - may increase the desire to play together with others when playing individually. For the same reason, players who are committed to their private goals may also be committed to their team's goal if it helps them to succeed in a game with intertwined goals. Overall, our findings indicate that practitioners should always carefully consider possible side-effects of mixing different game feature types (Morschheuser et al. 2017b). Further, cooperation cultivators should seek to design and implement gamification inspired by cooperative games instead of implementing individualistic game features, such as private badges or level systems, which are currently often used in communities and other collaborative technologies (Morschheuser, et al. 2016; 2017a; 2017b; Hamari et al. 2014).

By investigating Ingress, which is not only an augmented reality game, but also a crowdsourcing approach, this study provides particularly valuable insights for gamifying 
crowdsourcing initiatives and related systems where people work together to achieve common outcomes (Morschheuser et al. 2016; 2017a; Prestopnik \& Tang 2015). Our findings reveal that the implemented game features in Ingress represent an effective approach to cultivate strong and persistent cooperation. More than $73 \%$ of the respondents reported that they play Ingress for at least a year, and more than the half specified that when playing actively, they use the app multiple times per day. One possible reason for this strong engagement could be the great variety of applied game features. A recent review of gamified crowdsourcing systems revealed that crowdsourcing approaches, which strive for collaborative, emergent outcomes, may benefit from implementing manifold gamification approaches (Morschheuser et al. 2016; 2017a). By providing the opportunity to satisfy a broad spectrum of needs, the use of manifold gamification designs can engage broad target groups. Accordingly, managers and designers of crowdsourcing communities should consider applying manifold game design features when designing incentive mechanisms. On the other hand, for the reasons discussed above, designers should carefully consider possible effects of mixing cooperative, individualistic and competitive game features.

\subsection{Limitations and future research}

Similar to other studies conducted by online surveys, a shortcoming of this research is that the data were self-reported and that the participants were self-selected. Respondents of such surveys might not represent the entire population of a service or game, but might represent a population that shares a strong positive affinity to the object under investigation. In the context of our study, it can safely be assumed that the survey participants were highly engaged with the game and that less active users may be underrepresented in the sample. Thus, our findings may have neglected less active and less engaged players. This issue might be addressed in future research that particularly examines the intentions of less active players or players with little experience in cooperative games. 
Previous research indicates that less experienced users are inclined to follow suggestions and beliefs of those with whom they share goals rather than rely on their own knowledge, which may influence their group norms (Shen et al. 2011). On the other hand, experienced users are more likely to develop closer relationships with other group members and therefore perceive a stronger social identity with a group (Bagozzi \& Dholakia 2006). The study results show a more substantial relationship between cooperative gamification features and social identity as opposed to group norms. Future research could consider the effects of players' experience on group dynamics and we-intentions. Further, longitudinal studies will be needed to determine the psychological and behavioral outcomes of cooperative game features in relation to players' lifecycles.

Also, this study was conducted in the context of a particular cooperative game that seems to have implemented a set of successful game features that can invoke and cultivate weintentions. However, these identified and investigated cooperative game features strongly depend on the considered context. Although there are no a priori reasons to assume that our study context has influenced the findings on how games induce we-intentions, the results might be somewhat context-dependent. For instance, the strength of the effects between cooperative game features, group dynamics, and we-intentions may vary depending on the context and the applied cooperative game features. Future research that compares our study findings across different contexts could add to the generalizability of our results. Further, future research should try to increase the robustness of findings presented in this paper by combining de facto usage data with survey-based measured intentions and perceptions.

Finally, we encourage researchers to refine the understanding of moderating influences that may impact the cultivation of cooperation in games and gamified systems. Prior research in 
the context of gamification indicate that demographic and personality traits moderate perceptions and intentions of game features (Hamari \& Koivisto 2015a; Tondello et al. 2016). On the other hand, moderators such as group size (Brewer \& Kramer 1986) or culture (Tsai \& Bagozzi 2014) may moderate group dynamics and cooperative behaviors. In the special context of anticipated emotions, the moderating effects of gender and the extent of personal investment might be a reason why we have found no significant association between negative anticipated emotions and we-intentions among mostly male participants (cf. Bagozzi \& Dholakia 2006; Taylor, Bagozzi, \& Gaither 2005). We thus call for additional research into possible moderating effects. Future research that expands the understanding of factors that influence cooperation in games will not only contribute to a better understanding of this phenomenon, but will also support the design of gamification for cultivating cooperation in information systems and organizational contexts.

\section{References}

Ajzen, I. 1991. "The theory of planned behavior," Organizational Behavior and Human Decision Processes (50:2), pp. 179-211.

Anderson, J. C., and Gerbing, D. W. 1988. "Structural equation modeling in practice: A review and recommended two-step approach," Psychological Bulletin (103:3), pp. 411-423.

Arazy, O., Gellatly, I., Brainin, E., and Nov, O. 2016. "Motivation to share knowledge using wiki technology and the moderating effect of role perceptions," Journal of the Association for Information Science and Technology (67:10), pp. 2362-2378.

Armitage, C. J., and Conner, M. 2001. "Efficacy of the theory of planned behaviour: A metaanalytic review," British Journal of Social Psychology (40:4), pp. 471-499.

Bagozzi, R. P., and Dholakia, U. M. 2002. "Intentional social action in virtual communities," Journal of Interactive Marketing (16:2), pp. 2-21.

Bagozzi, R. P., and Dholakia, U. M. 2006. "Open Source Software User Communities: A Study of Participation in Linux User Groups," Management Science (52:7), pp. 1099-1115. 
Bagozzi, R. P., and Lee, K.-H. 2002. "Multiple routes for social influence: The role of compliance, internalization, and social identity," Social Psychology Quarterly (65:3), pp. 226-247.

Bessière, K., Seay, A. F., and Kiesler, S. 2007. "The ideal Elf: Identity exploration in World of Warcraft," CyberPsychology \& Behavior (10:4), pp. 530-535.

Beznosyk, A., Quax, P., Coninx, K., and Lamotte, W. 2012. "The influence of cooperative game design patterns for remote play on player experience," in Proceedings of the 10th Asia Pacific conference on computer human interaction - APCHI'12, Matsue-city, Shimane, Japan, pp. 11-19.

Björk, S., and Holopainen, J. 2005. Patterns in Game Design, Boston, Massachusetts: Charles River Media.

Blohm, I., Bretschneider, U., Leimeister, J. M., and Krcmar, H. 2011. "Does collaboration among participants lead to better ideas in IT-based idea competitions? An empirical investigation," International Journal Networking and Virtual Organisations (9:2), pp. 106122.

Bratman, M. E. 1997. "I Intend that We J," in Contemporary Action Theory, G. HolmstromHintikka \& R. Tuomela (eds.), Dordrecht, Netherlands: Kluwer, pp. 49-63.

Brewer, M. B., and Kramer, R. M. 1986. "Choice behavior in social dilemmas: Effects of social identity, group size, and decision framing," Journal of Personality and Social Psychology (50:3), pp. 543-549.

Brown, J. S., and Thomas, D. 2006. "You play World of Warcraft? You're hired!" $<$ https://www.wired.com/2006/04/learn/> (Accessed February 11, 2017).

Bui, A., Veit, D., and Webster, J. 2015. „Gamification - A Novel Phenomenon or a New Wrapping for Existing Concepts?" in Proceedings of the 36th International Conference on Information Systems - ICIS'15, Fort Worth, Texas, USA, pp. 1-21.

Chen, C.-H., Sun, C.-T., and Hsieh, J. 2008. "Player Guild Dynamics and Evolution in Massively Multiplayer Online Games," CyberPsychology \& Behavior (11:3), pp. 293-301.

Chen, Y., and Pu, P. 2014. "HealthyTogether: exploring social incentives for mobile fitness applications," in Proceedings of the Second International Symposium of Chinese CHI on Chinese CHI'14, Toronto, Ontario, Canada, pp. 25-34.

Cheung, C. M. K., Chiu, P., and Lee, M. K. O. 2011. "Online social networks: Why do students use Facebook?” Computers in Human Behavior, (27:4), pp. 1337-1343.

Cheung, C. M. K., and Lee, M. K. O. 2010. "A theoretical model of intentional social action in online social networks," Decision Support Systems (49:1), pp. 24-30. 
Chin, W. W. 1998. "The partial least squares approach for structural equation modelling," in Modern methods for business research, G. A. Marcoulides (ed.), London: Lawrence Erlbaum Associates, pp. 295-336.

Chin, W. W., Marcolin, B. L., and Newsted, P. R. 2003. "A partial least squares latent variable modeling approach for measuring interaction effects: Results from a Monte Carlo simulation study and an electronic-mail emotion/adoption study," Information Systems Research (14:2), pp. 189-217

Choi, D., and Kim, J. 2004. "Why people continue to play online games: In search of critical design factors to increase customer loyalty to online contents," CyberPsychology \& Behavior (7:1), pp. 11-24.

Christoph, K., Dorothée, H., and Peter, V. 2009. "The video game experience as "True" identification: A theory of enjoyable alterations of players' self-perception," Communication Theory (19:4), pp. 351-373.

Cole, H., and Griffiths, M. D. 2007. "Social Interactions in Massively Multiplayer Online Role-Playing Gamers," CyberPsychology \& Behavior (10:4), pp. 575-583.

Davis, F. D. 1989. "Perceived usefulness, perceived ease of use and user acceptance of information technology," MIS Quarterly (13:3), pp. 319-340.

Deterding, S. 2015. "The Lens of Intrinsic Skill Atoms: A Method for Gameful Design," Human-Computer Interaction, (30:3-4), pp. 294-335.

Dholakia, U. M., Bagozzi, R. P., and Pearo, L. K. 2004. "A social influence model of consumer participation in network- and small-group-based virtual communities," International Journal of Research in Marketing (21:3), pp. 241-263.

Diamantopoulos, A., and Siguaw, J. A. 2006. "Formative versus reflective indicators in organizational measure development: A comparison and empirical illustration," British Journal of Management (17:4), pp. 263-282.

Ducheneaut, N., Yee, N., Nickell, E., and Moore, R. J. 2007. "The Life and Death of Online Gaming Communities: A Look at Guilds in World of Warcraft," in Proceedings of the SIGCHI conference on Human Factors in computing systems - CHI'07, San Jose, California, USA, pp. 839-848.

Ducheneaut, N., Yee, N., Nickell, E., and Moore, R. J. 2006. "'Alone together?': exploring the social dynamics of massively multiplayer online games," in Proceedings of the SIGCHI conference on Human Factors in computing systems - CHI'06, Montréal, Québec, Canada, pp. 407-416.

El-Nasr, M. S., Aghabeigi, B., Milam, D., Erfani, M., Lameman, B., Maygoli, H., and Mah, S. 2010. "Understanding and evaluating cooperative games," in Proceedings of the 28th international conference on Human factors in computing systems - CHI'10, Atlanta, Georgia, USA, pp. 253-262. 
Ellemers, N., Kortekaas, P., and Ouwerkerk, J. W. 1999. "Self-categorization, commitment to the group and group self-esteem as related but distinct aspects of social identity," European Journal of Social Psychology (29), pp. 371-389

Fishbein, M., and Ajzen, I. 1975. Belief, attitude, intention and behavior: An introduction to theory and research, Reading, MA: Addison-Wesley.

Fornell, C., and Larcker, D. 1981. "Structural equation models with unobservable variables and measurement error," Journal of Marketing Research (18:1), pp. 39-50.

Geiger, D., and Schader, M. 2014. "Personalized task recommendation in crowdsourcing information systems - Current state of the art," Decision Support Systems (65), pp. 3-16.

Gilbert, M. 1989. On social facts, London: Routledge.

Gilbert, M. 1999. "Obligation and joint commitment," Utilitas (11:2), pp. 143-163.

Goh, D. H.-L., and Lee, C. S. 2011. "Perceptions, quality and motivational needs in image tagging human computation games," Journal of Information Science (37:5), pp. 515-531.

Hamari, J. 2013. "Transforming homo economicus into homo ludens: A field experiment on gamification in a utilitarian peer-to-peer trading service," Electronic Commerce Research and Applications (12:4), pp. 236-245.

Hamari, J. 2017. "Do badges increase user activity? A field experiment on the effects of gamification," Computers in Human Behavior (71), pp. 469-478.

Hamari, J. 2015a. Gamification - Motivation \& Effects. Helsinki, Finland: School of Business, Aalto University.

Hamari, J. 2015b. "Why do people buy virtual goods? Attitude toward virtual good purchases versus game enjoyment," International Journal of Information Management (35:3), pp. 299308.

Hamari, J., and Keronen, L. 2017a. "Why do people buy virtual goods: A meta-analysis," Computers in Human Behavior (71), pp. 59-69.

Hamari, J., and Keronen, L. 2017b. "Why do people play games? A meta-analysis," International Journal of Information Management (37:3), pp. 125-141.

Hamari, J., and Koivisto, J. 2015a. "Why do people use gamification services?" International Journal of Information Management (35:4), pp. 419-431.

Hamari, J., and Koivisto, J. 2015b. "'Working out for likes': An empirical study on social influence in exercise gamification," Computers in Human Behavior (50), pp. 333-347. 
Hamari, J., Koivisto, J., and Sarsa, H. 2014. "Does gamification work? - A literature review of empirical studies on gamification," in Proceedings of the 47th Hawaii International Conference on System Sciences - HICSS'14, Waikoloa, HI, USA, pp. 3025-3034.

Hamari, J., and Tuunanen, J. 2014. "Player types: A meta-synthesis," Transactions of the Digital Games Research Association (1:2), pp. 29-53.

Henseler, J., Ringle, C. M., and Sarstedt, M. 2015. "A new criterion for assessing discriminant validity in variance-based structural equation modeling," Journal of the Academy of Marketing Science (43:1), pp. 115-135.

Hsiao, C.-C., and Chiou, J.-S. 2012. "The impact of online community position on online game continuance intention: Do game knowledge and community size matter?" Information \& Management (49:6), pp. 292-300.

Hsu, C.-L., and Lu, H.-P. 2004. "Why do people play on-line games? An extended TAM with social influences and flow experience," Information \& Management (41:7), pp. 853-868.

Hsu, C.-Y., Tung, Y.-C., Wang, W.-H., and Wang, H.-Y. 2014. "Mute robot - cooperative gameplay through body language communication," in Proceedings of the extended abstracts of the 32nd annual ACM conference on human factors in computing systems - CHI EA'14, Toronto, Ontario, Canada, pp. 281-284.

Huang, E. 2012. "Online experiences and virtual goods purchase intention," Internet Research (22:3), pp. 252-274.

Hulsey, N., and Reeves, J. 2014. "The gift that keeps on giving: Google, Ingress, and the gift of surveillance," Surveillance \& Society (12:3), pp. 389-400.

Huotari, K., and Hamari, J. 2017. "A definition for gamification: anchoring gamification in the service marketing literature," Electronic Markets (27:1), pp. 21-31.

Hutter, K., Hautz, J., Füller, J., Mueller, J., and Matzler, K. 2011. "Communitition: The Tension between Competition and Collaboration in Community-Based Design Contests," Creativity and Innovation Management (20:1), pp. 3-21.

Johnson, D. W. 2003. "Social Interdependence: Interrelationships among theory, research, and practice," American Psychologist (58:11), pp. 934-945.

Johnson, D. W., and Johnson, R. T. 1989. Cooperation and competition: Theory and research, Edina, MN, US: Interaction Book Company.

Jöreskog, K. G., and Sörbom, D. 1996. LISREL 8 user's reference guide, Lincolnwood, USA: Scientific Software. 
Jung, J. H., Schneider, C., and Valacich, J. 2010. "Enhancing the Motivational Affordance of Information Systems: The Effects of Real-Time Performance Feedback and Goal Setting in Group Collaboration Environments," Management Science (56:4), pp. 724-742.

Lin, C.-P., and Bhattacherjee, A. 2008. "Elucidating Individual Intention to Use Interactive Information Technologies: The Role of Network Externalities," International Journal of Electronic Commerce (13:1), pp. 85-108.

Lin, K.-Y., and Lu, H.-P. 2011. "Why people use social networking sites: An empirical study integrating network externalities and motivation theory," Computers in Human Behavior (27:3), pp. 1152-1161.

Liu, D., Li, X., and Santhanam, R. 2013. "Digital Games and Beyond: What happens when players compete?” MIS Quarterly (37:1), pp. 111-124.

Liu, D., Santhanam, R., and Webster, J. 2017 (forthcoming). "Towards Meaningful Engagement: A Framework for Design and Research of Gamified Information Systems," MIS Quarterly.

Locke, E. A., and Latham, G. P. 1990. A theory of goal setting and task performance, Englewood Cliffs, NJ: Prentice-Hall.

Lowry, P. B., and Gaskin, J. 2014. "Partial least squares (PLS) structural equation modeling (SEM) for building and testing behavioral causal theory: When to choose it and how to use it," IEEE Transactions on Professional Communication (57:2), pp. 123-146.

Majchrzak, A., Rice, R. E., Malhotra, A., King, N., and Ba, S. 2000. "Technology adaptation: The case of a computer-supported inter-organizational virtual team," MIS Quarterly (24:4), pp. 569-600.

Malone, T. W. 1981. "Toward a Theory of Intrinsically Motivating Instruction," Cognitive Science (5:4), pp. 333-369.

Malone, T. W. 1982. "Heuristics for designing enjoyable user interfaces: Lessons from Computer Games," in Proceedings of the 1982 conference on Human factors in computing systems - CHI'82, Gaithersburg, Maryland, USA, pp. 63-68.

Marker, A. M., and Staiano, A. E. 2015. "Better together: Outcomes of cooperation versus competition in social exergaming," Games for Health Journal (4:1), pp. 25-30.

McAllister, D. J. 1995. "Affect-and cognition-based trust as foundations for interpersonal cooperation in organizations," Academy of Management Journal (38:1), pp. 24-59.

Morschheuser, B., Hamari, J., and Koivisto, J. 2016. "Gamification in crowdsourcing: A review," in Proceedings of the 49th Annual Hawaii International Conference on System Sciences - HICSS'16, Kauai, Hawaii, USA, pp. 4375-4384. 
Morschheuser, B., Hamari, J., and Koivisto, J. 2017a. "Gamified crowdsourcing: Conceptualization, literature review, and future agenda," International Journal of HumanComputer Studies (106), pp. 26-43.

Morschheuser, B., Maedche, A., and Walter, D. 2017b. "Designing cooperative gamification: Conceptualization and prototypical implementation," in Proceedings of the 20th ACM Conference on Computer-Supported Cooperative Work and Social Computing - CSCW'17, Portland, OR, USA, pp. 2410-2421.

Nash, J. 1953. “Two-Person cooperative games,” Econometrica (21:1), pp. 128-140.

Oliveira, M. J. de, and Huertas, M. K. Z. 2015. "Does Life Satisfaction influence the intention (We-Intention) to use Facebook?" Computers in Human Behavior (50), pp. 205-210.

Peng, W., and Hsieh, G. 2012. "The influence of competition, cooperation, and player relationship in a motor performance centered computer game," Computers in Human Behavior (28:6), pp. 2100-2106.

Perugini, M., and Bagozzi, R. P. 2001. "The role of desires and anticipated emotions in goaldirected behaviours: Broadening and deepening the theory of planned behaviour," British Journal of Social Psychology (40:1), pp. 79-98.

Plass, J. L., O’Keefe, P. A., Homer, B. D., Case, J., Hayward, E. O., Stein, M., and Perlin, K. 2013. "The impact of individual, competitive, and collaborative mathematics game play on learning, performance, and motivation," Journal of Educational Psychology (105:4), pp. 1050-1066.

Prestopnik, N. R., and Tang, J. 2015. "Points, stories, worlds, and diegesis: Comparing player experiences in two citizen science games," Computers in Human Behavior (52:C), pp. 492506.

Przybylski, A. K., Rigby, C. S., and Ryan, R. M. 2010. "A motivational model of video game engagement," Review of General Psychology (14:2), pp. 154-166.

Rempel, J. K., Holmes, J. G., and Zanna, M. P. 1985. "Trust in close relationships," Journal of Personality and Social Psychology (49:1), pp. 95-112.

Ribeiro, C., Farinha, C., Pereira, J., and Mira da Silva, M. 2014. "Gamifying requirement elicitation: Practical implications and outcomes in improving stakeholders collaboration," Entertainment Computing (5:4), pp. 335-345.

Rico, M., Martínez-Muñoz, G., Alaman, X., Camacho, D., and Pulido, E. 2011. "A programming experience of high school students in a virtual world platform," International Journal of Engineering Education (27:1), pp. 1-9.

Rigby, S. 2014. "Gamification and Motivation," in The Gameful World: Approaches, Issues, Applications, S. P. Walz \& S. Deterding (eds.), Cambridge, MA, USA: MIT Press, pp. 113137. 
Rigby, S., and Ryan, R. M. 2011. Glued To Games - How Video Games Draw Us In and Hold Us Spellbound, Santa Barbara, California: ABC-CLIO, LLC.

Ringle, C. M., Wende, S., and Becker, J.-M. 2015. "SmartPLS 3," $<$ http://www.smartpls.com> (Accessed February 11, 2017).

Rocha, J. B., Mascarenhas, S., and Prada, R. 2008. "Game Mechanics for Cooperative Games," in ZON Digital Games, N. Zagalo \& R. Prada (eds.), Universidade do Minho, pp. $72-80$.

Ryan, R. M., Rigby, C. S., and Przybylski, A. 2006. "The Motivational Pull of Video Games: A Self-Determination Theory Approach," Motivation and Emotion (30:4), pp. 344-360.

Schacht, S., and Maedche, A. 2015. "Project knowledge management while simply playing! Gaming mechanics in project knowledge management systems," in Gamification in Education and Business, T. Reiners \& L. C. Wood (eds.), Cham: Springer International Publishing, pp. 593-614.

Scharkow, M., Festl, R., Vogelgesang, J., and Quandt, T. 2015. "Beyond the "core-gamer": Genre preferences and gratifications in computer games," Computers in Human Behavior, 44, pp. 293-298.

Scheiner, C. W. 2015. "The motivational fabric of gamified idea competitions: The evaluation of game mechanics from a longitudinal perspective," Creativity and Innovation Management (24:2), pp. 341-352.

Seaborn, K., and Fels, D. I. 2015. "Gamification in theory and action: A survey," International Journal of Human-Computer Studies (74), pp. 14-31.

Searle, J. R. 1990. "Collective Intentions and Actions," in Intentions in communication, P. R. Cohen, J. Morgan, and M. Pollack (eds.), MIT Press, pp. 401-415.

Shen, A. X. L., Cheung, C. M. K., and Lee, M. K. O. 2013. "Perceived critical mass and collective intention in social media-supported small group communication," International Journal of Information Management (33:5), pp. 707-715.

Shen, A. X. L., Cheung, C. M. K., Lee, M. K. O., and Chen, H. 2011. "How social influence affects we-intention to use instant messaging: The moderating effect of usage experience," Information Systems Frontiers (13:2), pp. 157-169.

Shen, A. X. L., Lee, M. K. O., and Cheung, C. M. K. 2014. "Exploring online social behavior in crowdsourcing communities: A relationship management perspective," Computers in Human Behavior (40), pp. 144-151.

Shen, A. X. L., Lee, M. K. O., Cheung, C. M. K., and Chen, H. 2009. “An Investigation into Contribution I-Intention and We-Intention in Open Web-Based Encyclopedia: Roles of Joint Commitment and Mutual Agreement," in Proceeding of the 13th International Conference on Information Systems - ICIS'09, Phoenix, Arizona, USA, pp. 1-7. 
Sheng, L. Y. 2013. "Modelling learning from Ingress (Google's augmented reality social game)," in Proceedings of the 63rd Annual Conference International Council for Education Media - ICEM'13, Singapore, pp. 1-8.

Siu, K., Zook, A., and Riedl, M. O. 2014. "Collaboration versus competition: Design and evaluation of mechanics for games with a purpose," in Proceedings of the 9th International Conference on the Foundations of Digital Games - FDG'14, Lauderdale, Florida, USA, pp. $1-8$.

Smith, J. 2015. "A Million People Around You Are Playing an Alternate Reality Game You Can't See," <https://mic.com/articles/119366/one-million-people-around-you-are-playing-analternate-reality-game-you-can-t-see> (Accessed February 11, 2017).

Stets, J. E., and Burke, P. J. 2000. "Identity theory and social identity theory," Social Psychology Quarterly (63:3), pp. 224-237.

Straub, T., Gimpel, H., Teschner, F., and Weinhardt, C. 2015. "How (not) to Incent Crowd Workers,” Business \& Information Systems Engineering (57:3), pp. 167-179.

Tajfel, H. 1982. "Social psychology of intergroup relations," Annual Review of Psychology (33:1), pp. 1-39.

Takahashi, D. 2014. "Google's mobile game Ingress enables 7M players to create usergenerated missions," $<$ http://venturebeat.com/2014/09/25/googles-mobile-game-ingressenables-7m-players-to-create-user-generated-missions/> (Accessed August 27, 2016).

Taylor, S. D., Bagozzi, R. P., and Gaither, C. A. 2005. "Decision making and effort in the self-regulation of hypertension: Testing two competing theories," British Journal of Health Psychology (10:4), pp. 505-530.

Teng, C.-I., and Chen, W.-W. 2014. "Team participation and online gamer loyalty," Electronic Commerce Research and Applications (13:1), pp. 24-31.

Thom, J., Millen, D. R., Dimicco, J., and Street, R. 2012. "Removing Gamification from an Enterprise SNS," in Proceedings of the ACM 2012 conference on Computer Supported Cooperative Work - CSCW'12, Seattle, Washington, USA, pp. 1067-1070.

Tondello, G. F., Wehbe, R. R., Diamond, L., Busch, M., Marczewski, A., and Nacke, L. E. 2016. "The Gamification User Types Hexad Scale," in Proceedings of the 2016 Annual Symposium on Computer-Human Interaction in Play - CHI Play'16, Austin, TX, USA, pp. 229-243.

Tsai, H.-T., and Bagozzi, R. P. 2014. "Contribution Behavior in Virtual Communities: Cognitive, Emotional, and Social Influences," MIS Quarterly (38:1), pp. 143-163.

Tsai, H.-T., and Pai, P. 2014. "Why do newcomers participate in virtual communities? An integration of self-determination and relationship management theories," Decision Support Systems (57:1), pp. 178-187. 
Tuomela, R. 1995. The importance of us: A philosophical study of basic social notions, Stanford, CA: Stanford University Press.

Tuomela, R. 2000. Cooperation, Dordrecht: Springer-Science+Business Media, Vol. 82.

Tuomela, R. 2011. “Cooperation as joint action,” Analyse \& Kritik(33:1), pp. 65-86.

Turner, J. C. 1975. "Social comparison and social identity: Some prospects for intergroup behaviour," European Journal of Social Psychology (5:1), pp. 1-34.

Valacich, J. S., Dennis, A. R., and Connolly, T. 1994. "Idea Generation in Computer-Based Groups: A New Ending to an Old Story," Organizational Behavior and Human Decision Processes (57:3), pp. 448-467.

Velez, J. A., and Ewoldsen, D. R. 2013. "Helping behaviors during video game play," Journal of Media Psychology (25:4), pp. 190-200.

Vesa, M., Hamari, J., Harviainen, J. T., and Warmelink, H. 2017. "Computer games and organization studies," Organization Studies (38:2), 273-284.

Wasko, M. M., and Faraj, S. 2005. "Why Should I Share? Examining Social Capital and Knowledge Contribution in Electronic Networks of Practice," MIS Quarterly (29:1), pp. 3557.

$\mathrm{Wu}$, J., and Liu, D. 2007. "The effects of trust and enjoyment on intention to play online games," Journal of Electronic Commerce Research (8:2), pp. 128-140.

Yee, N. 2006. "Motivations for Play in Online Games," CyberPsychology \& Behavior (9:6), pp. $772-775$.

Zagal, J. P., Rick, J., and Hsi, I. 2006. "Collaborative games: Lessons learned from board games," Simulation \& Gaming (37:1), pp. 24-40.

Zhang, X., Venkatesh, V., and Brown, S. A. 2011. "Designing Collaborative Systems to Enhance Team Performance," Journal of the Association for Information System (12:8), pp. $556-584$.

Zhao, Y., and Zhu, Q. 2014. "Effects of extrinsic and intrinsic motivation on participation in crowdsourcing contest," Online Information Review (38:7), pp. 896-917.

Zhong, Z.-J. 2011. "The effects of collective MMORPG (Massively Multiplayer Online RolePlaying Games) play on gamers' online and offline social capital," Computers in Human Behavior (27:6), pp. 2352-2363. 


\section{Appendix A}

\section{A.1. Questions asked to determine the nature of a game design feature in Ingress:}

I find that this game feature ...

(«Description of the functionality»)

... is of individual nature

(5-point Likert scale: strongly disagree - strongly agree)

$\ldots$ is of competitive nature

(5-point Likert scale: strongly disagree - strongly agree)

$\ldots$ is of cooperative nature

(5-point Likert scale: strongly disagree - strongly agree)

\section{A.2. Results of the Ingress feature categorization:}

\begin{tabular}{|c|c|c|c|}
\hline Identified game feature of Ingress & $\begin{array}{l}\text { Individualistic } \\
\text { game features }\end{array}$ & $\begin{array}{l}\text { Cooperative game } \\
\text { features }\end{array}$ & $\begin{array}{l}\text { Competitive game } \\
\text { features }\end{array}$ \\
\hline Factions & & $X^{*}$ & \\
\hline Action Points (AP) & $\mathrm{x}$ & & \\
\hline Mind Units (MU) & & $X^{*}$ & \\
\hline Agent level & $x$ & & \\
\hline Medals & $\mathrm{X}$ & & \\
\hline Mission badges & $x$ & & \\
\hline Agent stats & $\mathrm{X}$ & & \\
\hline Deploy Resonators & & $X^{*}$ & \\
\hline Recharge Resonators & & $X^{*}$ & \\
\hline COMM (in-game chat) & & $X^{*}$ & \\
\hline First Saturday (FS) events & & $\mathrm{X}$ & \\
\hline XM Anomalies & & $X^{*}$ & \\
\hline Personal avatar & $\mathrm{X}$ & & \\
\hline Weapons & & & $\mathrm{X}$ \\
\hline Power Cubes & $\mathrm{x}$ & & \\
\hline Mods & & $X^{*}$ & \\
\hline Playing of missions & $x$ & & \\
\hline Mission days & $(x)$ & $x$ & \\
\hline Hacking of portals & C & C & $\mathrm{C}$ \\
\hline Attacking portals & & & $\mathrm{X}$ \\
\hline Takeover portals & & $X^{*}$ & \\
\hline Upgrade portals & & $X^{*}$ & \\
\hline Checkpoints and cycles & & $X^{*}$ & \\
\hline
\end{tabular}


$\mathrm{X}=$ primary perceived category of the game feature.

$(x)=$ secondary perceived category of the game feature. A minority of experts perceived this feature as part of the corresponding category.

* = features that were perceived as having both competitive traits (on an intergroup level) as well as cooperative traits (on an intragroup level). For such cooperative-competitive features (e.g. factions), we sought to carefully identify the cooperative aspects before developing the corresponding survey items.

$\mathrm{C}=$ feature that was perceived as a core game mechanic of the game. Thus, no clear assignment to one of the feature categories could be made. 